\title{
Another Look at GAAP versus The Street: An Empirical Assessment of Measurement Error Bias
}

\author{
Daniel A. Cohen \\ Stern School of Business \\ New York University \\ New York, NY 10012
}

Rebecca N. Hann*

Leventhal School of Accounting University of Southern California, Los Angeles, California 90089-1421

\section{Maria Ogneva}

Leventhal School of Accounting University of Southern California, Los Angeles, California 90089-1421

November 2006

* Corresponding author. Email: rebecca.hann@marshall.usc.edu. Tel: (213) 740-6939

We thank Larry Brown, Mei Cheng, Ted Christensen (the discussant), Mark DeFond, Zhaoyang Gu, Il-Horn Hann, Russell Lundholm (the editor), K. R. Subramanyam, Jieying Zhang and seminar participants at the 2006 RAST Conference (INSEAD) and USC for their valuable comments and suggestions. 


\title{
Another Look at GAAP versus The Street: An Empirical Assessment of Measurement Error Bias
}

\begin{abstract}
Bradshaw and Sloan (2002) document a significant increase in the difference between the earnings response coefficients (ERCs) for GAAP and Street (I/B/E/S) earnings over the 1990s, suggesting that the market has become increasingly reliant or fixated on Street earnings. In this study we investigate whether, alternatively, an "errors in variables" problem caused by a mismatch between the definitions of realized and expected earnings drives the ERC divergence. Our findings suggest that results from conventional analyses of GAAP and Street ERCs, including the ERC divergence pattern, are significantly contaminated by measurement errors in earnings surprises.
\end{abstract}

Keywords: capital markets, analyst forecasts, earnings response coefficients, GAAP earnings, Street earnings, measurement error.

JEL Classification: M4 
Given managers and analysts' increasing emphasis on Street earnings, a stream of recent research examines the relative information content of GAAP versus Street earnings. ${ }^{1}$ Bradshaw and Sloan (2002), for instance, document a significant increase in the difference between the earnings response coefficients (ERCs) for GAAP and Street (I/B/E/S) earnings over the 1990s. They suggest that this finding is consistent with two possible explanations: (1) investors have become increasingly reliant on Street earnings, as managers exclude more transitory components to arrive at a more informative earnings figure, and (2) investors have become increasingly fixated on Street earnings, as managers opportunistically exclude more negative earnings components in an effort to realize higher valuations. In this paper, we examine a third, but not mutually exclusive, explanation for the observed ERC divergence, namely, measurement error bias in GAAP and Street ERCs.

Recent studies (e.g., Bradshaw, 2003; Berger, 2005; Abarbanell and Lehavy, 2006) argue that the GAAP versus Street literature is plagued by measurement errors caused by a mismatch between the definitions of realized and expected earnings. Two specific measurement errors have been noted: (1) the $I / B / E / S$ Adjustment Error, which arises because $\mathrm{I} / \mathrm{B} / \mathrm{E} / \mathrm{S}$ uses different definitions for actual and forecasted earnings for the pre-1992 period, and (2) the GAAP Expectation Error, which arises because researchers use I/B/E/S forecasts as a proxy for GAAP earnings expectations. While these two errors have been highlighted in prior research, the degree to which and the mechanisms through which they affect the difference between GAAP and Street ERCs remain largely unexplored. The purpose of this study is to address these questions. To do so, we begin by developing a formalized framework to better understand the properties of these two errors and their different implications for GAAP and Street ERCs. We then empirically

\footnotetext{
${ }^{1}$ While most studies use the actual earnings reported by commercial forecast data providers such as $\mathrm{I} / \mathrm{B} / \mathrm{E} / \mathrm{S}$ to proxy for Street earnings (e.g., Bradshaw and Sloan, 2002; Brown and Sivakumar, 2003; Doyle, Lundholm, and Soliman, 2003; Bhattacharya, Black, Christensen, and Larson, 2003), others use pro forma earnings figures collected from press releases (e.g., Bhattacharya et al., 2003; Lougee and Marquardt, 2004; Johnson and Schwartz, 2005).
} 
assess the extent to which these errors affect the documented ERC divergence pattern. Finally, we discuss the implications of these errors for research design and inferences.

We define the $I / B / E / S$ Adjustment Error and the GAAP Expectation Error as follows. The $I / B / E / S$ Adjustment Error is a measurement error in the realized component of Street earnings surprises (Street forecast errors). ${ }^{2}$ This error arises because, prior to the early $1990 \mathrm{~s}, \mathrm{I} / \mathrm{B} / \mathrm{E} / \mathrm{S}$ did not always adjust actual earnings to exclude items not forecasted by analysts, thereby creating a mismatch between its actual (realized) and forecasted (expected) earnings; in the early 1990s, $\mathrm{I} / \mathrm{B} / \mathrm{E} / \mathrm{S}$ undertook procedural and definitional changes to correct this error (hereafter, the I/B/E/S "regime shift"). ${ }^{3}$ The GAAP Expectation Error is a measurement error in the expected component of GAAP earnings surprises (GAAP forecast errors). ${ }^{4}$ This error arises from the use of $\mathrm{I} / \mathrm{B} / \mathrm{E} / \mathrm{S}$ forecasts to proxy for GAAP earnings expectations: since $\mathrm{I} / \mathrm{B} / \mathrm{E} / \mathrm{S}$ forecasts tend to exclude certain items that are required under GAAP (e.g., special items), there is a mismatch between the definitions of realized and expected GAAP earnings, leading to a classic "errors in variables" problem. ${ }^{5}$

Using our formalized framework, we show that the $I / B / E / S$ Adjustment Error induces a downward bias in Street ERC in the pre-regime shift period. After the regime shift, this error and its corresponding downward bias are mitigated. Thus, the documented temporal increase in the difference between GAAP and Street ERCs is likely to be overstated (i.e., the extent of the ERC divergence is overstated). Further, we show that the GAAP Expectation Error induces a

\footnotetext{
${ }^{2}$ This error is discussed in Abarbanell and Lehavy (2002, 2006), Bradshaw and Sloan (2002), and Bradshaw (2003).

${ }^{3}$ Following Abarbanell and Lehavy (2006), we refer to the procedural and definitional changes as the I/B/E/S "regime shift" throughout the paper.

${ }^{4}$ Bradshaw (2003) is among the first to discuss this classic "errors in variables" problem; see also Bhattacharya et al. (2003) and Berger (2005).

${ }^{5}$ Note that while the estimated GAAP and Street earnings surprises are the same in the pre-regime shift period (i.e., when $\mathrm{I} / \mathrm{B} / \mathrm{E} / \mathrm{S}$ reports a GAAP figure as its actual earnings, both surprise measures are equal to the difference between realized GAAP earnings and I/B/E/S forecasted earnings), the true GAAP and Street earnings surprises are different. Therefore, the two measurement errors (I/B/E/S Adjustment Error and GAAP Expectation Error) are not the same. See Section 1 for a more detailed discussion.
} 
downward bias in GAAP ERC, both before and after the regime shift. Thus, the difference between the GAAP and Street ERCs is likely to be overstated for the entire time period.

We perform two sets of empirical analyses. First, we decompose GAAP and Street ERCs into two components, specifically, the covariance between stock returns and forecast errors, and the variance of forecast errors. Second, we estimate reverse regressions (i.e., we regress GAAP and Street forecast errors on unexpected stock returns), a classic remedy for mitigating measurement error bias (e.g., Collins and Kothari, 1989). In the ERC decomposition analysis, three interesting observations emerge. First, we find an increased divergence in the difference between the variances of Street and GAAP forecast errors, which closely mirrors the ERC divergence pattern. Second, the source of the variance divergence stems primarily from a downward shift in the variance of Street forecast errors (with no apparent decline in the variance of GAAP forecast errors) in the early 1990s, around the time of $\mathrm{I} / \mathrm{B} / \mathrm{E} / \mathrm{S}$ ' regime shift. Third, unlike the temporal trend in the variance difference, we do not find a contemporaneous increase in the difference between Street and GAAP covariances; in fact, there is a mild decrease in the covariance difference, which works against finding the ERC divergence pattern. Overall, the observed ERC divergence appears to be driven solely by differences in the variances of GAAP and Street forecast errors. These results are consistent with: (1) a high level of noise in Street forecast errors, which translates into a downward bias in Street ERC, in the pre-regime shift period, and (2) a decrease in the noisiness of Street forecast errors after the regime shift, which mitigates the downward bias in Street ERC.

The reverse regression analysis shows no significant upward trend in the difference between the reverse Street and GAAP ERC coefficients. Specifically, when we regress unexpected stock returns on GAAP and Street forecast errors and an interaction term between forecast errors and a time trend variable, we find no significant difference between the Street and 
GAAP interaction terms. Recall that it is the $I / B / E / S$ Adjustment Error that creates a spurious ERC divergence pattern. Hence, not finding increased divergence in the reverse ERCs is consistent with the previously documented ERC divergence pattern being attributable to the I/B/E/S Adjustment Error.

Because the reverse regression approach mitigates both measurement errors, it is difficult to parse out the effects of removing only the GAAP Expectation Error. To shed light on the significance of GAAP Expectation Error, we estimate pooled and yearly reverse regressions for the subperiod that is likely to be free of the $I / B / E / S$ Adjustment Error, that is, the post-regime shift period (1993 to 2003). For the pooled sample, we find that the reverse ERC difference remains statistically significant. This result is not surprising because, even absent the GAAP Expectation Error, we would expect to find a positive ERC difference as long as Street earnings exclude some transitory components from GAAP earnings. For the yearly regressions, however, we find that while the ERC difference (from the original regressions) is significant in all eleven years, the reverse ERC difference (from the reverse regressions) is significant in only five out of the eleven years (and only one out of five years from 1993 to1997). These results suggest that the GAAP Expectation Error has a significant effect on the documented ERC differences.

Our study contributes to the literature in several ways. First, our results provide insights on the source of the increased reaction to Street (over GAAP) earnings, as indicated by the documented ERC divergence. Specifically, we find that measurement errors in earnings surprises contribute significantly to this finding. Note that while Abarbanell and Lehavy (2006) also examine the ERC divergence pattern, our papers differ in at least two respects. Abarbanell and Lehavy show that a small number of extreme observations drive the divergence in ERCs, whereas we present evidence on the underlying cause of the observed divergence and provide a framework that formally describes the measurement errors in earnings surprises and their impact 
on GAAP and Street ERCs. Moreover, Abarbanell and Lehavy show the effect of excluding extreme observations on the first moment of the forecast error distribution (i.e., the mean effect), whereas our analysis demonstrates the importance of analyzing the second moment of the distribution (i.e., the variance effect). In particular, we find that the ERC divergence is largely attributable to the variance differences (as opposed to mean differences) between GAAP and Street forecast errors.

Second, our finding that the ERC divergence pattern stems from a decrease in the variance of Street forecast errors around the time of the $\mathrm{I} / \mathrm{B} / \mathrm{E} / \mathrm{S}$ regime shift has important implications for any study that uses $\mathrm{I} / \mathrm{B} / \mathrm{E} / \mathrm{S}$ forecast errors as an explanatory variable, especially for temporal and trend analyses that include the period prior to 1992 (e.g., Collins, Li, and Xie, 2005). Specifically, ignoring the correction of the $I / B / E / S$ Adjustment Error would result in overstating the importance of other causes for the change in the regression coefficients on forecast errors, such as an increase in the information content of earnings. Future research that employs $\mathrm{I} / \mathrm{B} / \mathrm{E} / \mathrm{S}$ forecast errors as a proxy for earnings surprises should therefore exclude the pre-1992 sample period to avoid biases introduced by the I/B/E/S Adjustment Error. ${ }^{6}$

Lastly, the implications of the GAAP Expectation Error can be extended to any nonGAAP earnings figure (e.g., pro forma earnings). When $\mathrm{I} / \mathrm{B} / \mathrm{E} / \mathrm{S}$ forecasts are used to proxy for the expectation of a non-GAAP earnings figure, the resulting non-GAAP ERC is subject to a downward measurement error bias. A possible avenue for future research is to explore the properties of other expectation proxies (e.g., a modified I/B/E/S forecast). For instance, future research may consider estimating reverse earnings-returns regressions to assess the measurement errors in alternative earnings surprise proxies.

\footnotetext{
${ }^{6}$ For instance, the findings of some recent studies that use pre-1992 I/B/E/S data to construct forecast errors (e.g., Doyle and Soliman, 2004; Collins et al., 2005; Doyle, Lundholm, and Soliman, 2006) may be affected because of the measurement error in earnings surprises that arises from the I/B/E/S Adjustment Error.
} 
The rest of the paper is organized as follows. Section 1 presents our empirical propositions. Section 2 discusses our sample selection and variable definitions. Section 3 reports our empirical results and discusses implications for future research. Section 4 provides some robustness tests. Section 5 concludes.

\section{Empirical Assessment of Measurement Error Biases}

In the GAAP versus Street earnings literature, GAAP and Street earnings response coefficients (ERCs) are obtained by regressing stock returns on the two alternative measures of earnings surprises. In this section, we explore the potential biases introduced by using noisy measures of earnings surprises in estimating GAAP and Street ERCs.

An ERC is a regression coefficient estimate that is expressed as follows:

$$
E R C=\frac{\operatorname{cov}(F E, U R)}{\operatorname{var}(F E)},
$$

where $F E$ denotes unexpected earnings (i.e., earnings surprise) and $U R$ denotes the unexpected return associated with an earnings shock. If an earnings surprise is measured without error $(F \hat{E}=F E)$, the estimate of the ERC is unbiased:

$$
E R C=E \hat{R} C=\frac{\operatorname{cov}(F \hat{E}, \hat{U} R)}{\operatorname{var}(F \hat{E})}
$$

However, if an earnings surprise is measured with error (i.e., $F \hat{E}=F E+\eta$ ), the ERC estimate is biased toward zero: ${ }^{7}$

$$
E R C>E \hat{R} C=\frac{\operatorname{cov}(F \hat{E}, \hat{U} R)}{\operatorname{var}(F \hat{E})}=\frac{\operatorname{cov}(F E, U R)}{\operatorname{var}(F E)+\operatorname{var}(\eta)} .
$$

\footnotetext{
${ }^{7}$ Throughout the paper, we assume that the true unexpected earnings is uncorrelated with the measurement error, that is, $\operatorname{var}(F \hat{E})=\operatorname{var}(F E)+\operatorname{var}(\eta)$.
} 
Measurement error in an earnings surprise can result from an error in either the realized or the expected earnings measure, that is, from a misalignment between either the realized value and its empirical counterpart, or the expectation and its empirical counterpart.

In the context of this study, there are two potential sources of error that could bias GAAP and Street ERCs: (1) a downward bias in Street ERC prior to the regime shift undertaken by $\mathrm{I} / \mathrm{B} / \mathrm{E} / \mathrm{S}$ to correct for the misalignment between its definitions of reported (actual) and forecasted earnings (i.e., the $I / B / E / S$ Adjustment Error), and (2) a downward bias in GAAP ERC for the entire sample period due to $\mathrm{I} / \mathrm{B} / \mathrm{E} / \mathrm{S}$ forecasts being used as proxies for GAAP earnings expectations (i.e., the GAAP Expectation Error). We explore the implications of these two errors in the following stylized setting. Our main variables of interest are $E P S_{G A A P}$ and $E P S_{\text {Street }}$, realized GAAP and Street earnings per share, respectively, where GAAP earnings is defined as Compustat's earnings before extraordinary items and Street earnings is given by $\mathrm{I} / \mathrm{B} / \mathrm{E} / \mathrm{S}$ ' earnings figure. The difference between the two measures, $E P S_{D i f f}$ (i.e., $E P S_{G A A P}-E P S_{\text {Street }}$ ), is the component excluded by the Street. In estimating earnings surprises, prior studies use earnings reported by $\mathrm{I} / \mathrm{B} / \mathrm{E} / \mathrm{S}$ to proxy for Street earnings, and earnings forecasts provided by $\mathrm{I} / \mathrm{B} / \mathrm{E} / \mathrm{S}$ to proxy for both GAAP and Street earnings expectations. However, from the discussion of measurement error above, if $\mathrm{I} / \mathrm{B} / \mathrm{E} / \mathrm{S}$ ' reported EPS measures are noisy estimates of realized values, or if $\mathrm{I} / \mathrm{B} / \mathrm{E} / \mathrm{S}$ ' forecasted EPS measures are noisy estimates of expected values, the empirical estimate for each earnings surprise measure consists of both a "true surprise" and a "measurement error" component. In the remainder of this section, we explore the implications of the two measurement errors on the estimated GAAP and Street ERCs. 


\subsection{I/B/E/S Adjustment Error: Misalignment between Actual and Forecasted $1 / B / E / S$}

\section{Earnings Prior to the $I / B / E / S$ Regime Shift}

The first type of measurement error-I/B/E/S Adjustment Error-stems from a misalignment between the realized value of Street earnings and its empirical counterpart, which introduces a bias into the estimated Street ERC. This error is related to the procedural and definitional changes (regime shift) undertaken by $\mathrm{I} / \mathrm{B} / \mathrm{E} / \mathrm{S}$ in the early 1990 s to correct for the misalignment between $\mathrm{I} / \mathrm{B} / \mathrm{E} / \mathrm{S}$ ' actual and forecasted earnings. Prior studies in the GAAP versus Street literature provide a detailed discussion of these changes. In particular, Bradshaw and Sloan (2002) note that "conversations with $\mathrm{I} / \mathrm{B} / \mathrm{E} / \mathrm{S}$ confirm that this break point [early 1990s] corresponds to the time during which they began actively redefining 'actual' earnings to exclude certain items." (Bradshaw and Sloan, 2002, p.52). Similarly, Abarbanell and Lehavy (2006) mention that "[it] is clear from conservations with I/B/E/S officials that events in the early 1990s did cause procedural changes over the next year. These changes were designed to align more closely the definition of earnings to be forecasted by analysts to the definition of actual realized earnings." (Abarbanell and Lehavy, 2006, p.10). However, these studies do not directly address the potential measurement error bias in estimated ERC values induced by the regime shift.

To illustrate the potential effects of the $I / B / E / S$ Adjustment Error, we first define the true Street earnings surprise as:

$$
\begin{array}{rll}
\text { True Street Earnings Surprise: } F E_{\text {Street }} & = & E P S_{\text {Street }}-\mathrm{E}\left(E P S_{\text {Street }}\right) \text {, } \\
\text { where } & & \\
E P S_{\text {Street }} & = & \text { Realized Street Earnings } \\
\mathrm{E}\left(E P S_{\text {Street }}\right) & = & \text { Expected Street Earnings. }
\end{array}
$$

We make the following two assumptions in our stylized setting: (1) I/B/E/S forecasts $\left(F E P S_{\text {Street }}\right)$ are a perfect proxy for Street earnings expectations at all times (i.e., $\left.F E P S_{\text {Street }}=\mathrm{E}\left(E P S_{\text {Street }}\right)\right)$; (2) 
prior to $\mathrm{I} / \mathrm{B} / \mathrm{E} / \mathrm{S}$ ' regime shift, $\mathrm{I} / \mathrm{B} / \mathrm{E} / \mathrm{S}$ ' actual earnings correspond to GAAP earnings $\left(E P S_{G A A P}\right)$ as opposed to Street earnings $\left(E P S_{\text {Street }}\right)$. Below we summarize these assumptions and derive the estimated Street earnings surprise for the pre-regime shift period:

\section{Pre-Regime Shift Period}

Assumptions:

$$
\begin{aligned}
& \text { Empirical proxy for } E P S_{\text {Street }}=\mathrm{I} / \mathrm{B} / \mathrm{E} / \mathrm{S} \text { ' actual earnings }=E P S_{G A A P} \\
& \text { Empirical proxy for } \mathrm{E}\left(E P S_{\text {Street }}\right)=\mathrm{I} / \mathrm{B} / \mathrm{E} / \mathrm{S} \text { ' forecasted earnings }=F E P S_{\text {Street }} \\
& F E P S_{\text {Street }}=\mathrm{E}\left(E P S_{\text {Street }}\right) \text {. }
\end{aligned}
$$

$$
\begin{aligned}
\text { Estimated Street Earnings Surprise: } \quad F \hat{E}_{\text {Street }} & =E P S_{G A A P}-F E P S_{\text {Street }} \\
& =E P S_{G A A P}-\mathrm{E}\left(E P S_{\text {Street }}\right) \\
& =E P S_{\text {Street }}+E P S_{\text {Diff }}-\mathrm{E}\left(E P S_{\text {Street }}\right) \\
& =F E_{\text {Street }}+E P S_{\text {Diff }} \\
& =F E_{\text {Street }}+\text { Measurement Error. }
\end{aligned}
$$

From the above, we see that the measurement error in the earnings surprise estimate is equal to $E P S_{D i f f}$, the difference between the realized GAAP and Street EPS (i.e., $\left.E P S_{G A A P}-E P S_{\text {Street }}\right)^{8}$

Therefore, the estimated earnings surprise coefficient is biased downward in the pre-regime shift period: ${ }^{9}$

$$
\hat{E} R C_{\text {Street }}=\frac{\operatorname{cov}\left(F E_{\text {Street }}, U R\right)+\operatorname{cov}\left(E P S_{\text {Diff }}, U R\right)}{\operatorname{var}\left(F E_{\text {Street }}\right)+\operatorname{var}\left(E P S_{\text {Diff }}\right)}<E R C_{\text {Street. }}
$$

\footnotetext{
${ }^{8}$ Note that $E P S_{\text {Diff }}$ is the difference between the true realized GAAP and Street EPS and not the difference between the estimated GAAP and Street EPS. Hence, while the empirical proxies for GAAP and Street EPS are the same for the pre-regime shift period (i.e., both are equal to $E P S_{G A A P}$ ) and hence the difference between the estimated GAAP and Street EPS is equal to zero in our model, the true $E P S_{D i f f}$ is not equal to zero.

${ }^{9}$ Note that because $\mathrm{E}\left(E P S_{\text {Diff }}\right)$ is uncorrelated with the unexpected return (UR) by definition, the following two covariance terms are equivalent to each other: $\operatorname{cov}\left(F E_{\text {Diff, }}, \mathrm{UR}\right)=\operatorname{cov}\left(E P S_{\text {Diff, }}, \mathrm{UR}\right)$, where $F E_{\text {Diff }}$ is defined as $F E_{G A A P}$ $-F E_{\text {Street. }}$ Therefore, we can rewrite the estimated Street ERC expression as follows:

$$
\hat{E} R C_{\text {Street }}=\frac{\operatorname{cov}\left(F E_{\text {Street }}, U R\right)+\operatorname{cov}\left(F E_{\text {Diff }}, U R\right)}{\operatorname{var}\left(F E_{\text {Street }}\right)+\operatorname{var}\left(E P S_{D f f}\right)} .
$$

It is then easy to show that $\hat{E} R C_{\text {Street }}$ is biased downward whenever the following inequality holds:

$$
\frac{\operatorname{cov}\left(F E_{\text {Street }}, U R\right)}{\operatorname{var}\left(F E_{\text {Street }}\right)}>\frac{\operatorname{cov}\left(F E_{\text {Diff }}, U R\right)}{\operatorname{var}\left(E\left(E P S_{\text {Diff }}\right)\right)+\operatorname{var}\left(F E_{\text {Diff }}\right)} \text {. }
$$

This inequality is expected to hold at all times given that the expression on the left-hand side is the true ERC for Street earnings, while the expression on the right-hand side is a downward-biased ERC for excluded items.
} 
Now assume that after the regime shift, I/B/E/S completely eliminates the misalignment between actual and forecasted earnings. The model assumptions and estimated Street earnings surprise for the post-regime shift period are then given as follows:

\section{Post-Regime Shift Period}

Assumptions:

Empirical proxy for $E P S_{\text {Street }} \quad=\mathrm{I} / \mathrm{B} / \mathrm{E} / \mathrm{S}^{\prime}$ actual earnings $\quad=E P S_{\text {Street }}$

Empirical proxy for $\mathrm{E}\left(E P S_{\text {Street }}\right)=\mathrm{I} / \mathrm{B} / \mathrm{E} / \mathrm{S}$ ' forecasted earnings $=F E P S_{\text {Street }}$ $F E P S_{\text {Street }}=\mathrm{E}\left(E P S_{\text {Street }}\right)$.

$$
\text { Estimated Street Earnings Surprise: } \quad \begin{aligned}
F \hat{E}_{\text {Street }} & =E P S_{\text {Street }}-F E P S_{\text {Street }} \\
& =E P S_{\text {Street }}-\mathrm{E}\left(E P S_{\text {Street }}\right) \\
& =F E_{\text {Street. }}
\end{aligned}
$$

From the above, the post-regime shift Street earnings surprise is measured without error. Thus, after the regime shift the estimated earnings surprise coefficient is equal to its theoretical counterpart:

$$
\hat{E} R C_{\text {Street }}=\frac{\operatorname{cov}\left(F E_{\text {Street }}, U R\right)}{\operatorname{var}\left(F E_{\text {Street }}\right)}=E R C_{\text {Street. }}
$$

The bias introduced by the $I / B / E / S$ Adjustment Error is consistent with the observed divergence pattern in ERCs, that is, the estimated Street ERC is biased downward prior to $\mathrm{I} / \mathrm{B} / \mathrm{E} / \mathrm{S}$ ' regime shift. As $\mathrm{I} / \mathrm{B} / \mathrm{E} / \mathrm{S}$ corrects for the misalignment between actual and forecasted earnings, there is less measurement error in the Street's earnings surprise, and hence, the downward bias in Street ERC is alleviated. We formally summarize this discussion in the following proposition:

Proposition 1: The $I / B / E / S$ Adjustment Error induces a downward bias in Street ERC in the pre-regime shift period. This downward bias is mitigated after the $\mathrm{I} / \mathrm{B} / \mathrm{E} / \mathrm{S}$ regime shift. Thus, the temporal increase in the differences between Street and GAAP ERCs is overstated (i.e., the ERC divergence pattern is overstated). 
The effect of the $I / B / E / S$ Adjustment Error bias is illustrated in Panel A of Figure 1 . The dotted line represents a trend in the true unbiased Street ERC, and the solid line represents a trend in the estimated Street ERC. The $I / B / E / S$ Adjustment Error generates a downward bias in the early years, and the correction of the $I / B / E / S$ Adjustment Error increases the slope for the Street ERC trend line, creating a spurious divergence pattern.

\subsection{GAAP Expectation Error: Using I/B/E/S Forecasts to Proxy for GAAP Earnings}

\section{Expectations}

The second type of measurement error-GAAP Expectation Error-stems from a misalignment between the expected value of GAAP earnings and its empirical counterpart, which introduces a bias into estimated GAAP ERC. In particular, this error stems from the unavailability of GAAP earnings forecasts, which is a limitation faced by many studies in the GAAP versus Street earnings literature (as discussed in Bradshaw (2003) and Berger (2005)). In the absence of a better proxy, the GAAP earnings surprise is measured as the difference between realized GAAP earnings and $\mathrm{I} / \mathrm{B} / \mathrm{E} / \mathrm{S}$ ' earnings forecast, despite the fact that the latter measure excludes certain items that are included in GAAP earnings.

To illustrate the potential bias induced by this error, we first define the true GAAP earnings surprise as follows:

$$
\begin{array}{rll}
\text { True GAAP Earnings Surprise: } F E_{G A A P} & = & E P S_{G A A P}-\mathrm{E}\left(E P S_{G A A P}\right), \\
\text { where } & & \\
E P S_{G A A P} & = & \text { Realized GAAP Earnings } \\
\mathrm{E}\left(E P S_{G A A P}\right) & = & \text { Expected GAAP Earnings. }
\end{array}
$$

We again assume that I/B/E/S forecasts are a perfect proxy for Street earnings expectations (i.e., $\left.F E P S_{\text {Street }}=\mathrm{E}\left(E P S_{\text {Street }}\right)\right)$ at all times. The model's assumptions, estimated GAAP earnings surprise, and corresponding measurement error can then be summarized as follows: 
Assumptions:

Empirical proxy for $E P S_{G A A P}=$ Compustat earnings $=E P S_{G A A P}$

Empirical proxy for $\mathrm{E}\left(E P S_{G A A P}\right)=\mathrm{I} / \mathrm{B} / \mathrm{E} / \mathrm{S}$ ' forecasted earnings $=F E P S_{\text {Street }}$ $F E P S_{\text {Street }}=\mathrm{E}\left(E P S_{\text {Street }}\right)$.

Estimated GAAP Earnings Surprise:

$$
\begin{aligned}
F \hat{E}_{\text {GAAP }} & =E P S_{\text {GAAP }}-F E P S_{\text {Street }} \\
& =E P S_{\text {GAAP }}-\mathrm{E}\left(E P S_{\text {Street }}\right) \\
& =E P S_{\text {GAAP }}-\left[\mathrm{E}\left(E P S_{\text {GAAP }}\right)-\mathrm{E}\left(E P S_{\text {Diff }}\right)\right] \\
& =F E_{\text {GAAP }}+\mathrm{E}\left(E P S_{\text {Diff }}\right) \\
& =F E_{\text {GAAP }}+\text { Measurement Error }
\end{aligned}
$$

Note that while the estimated GAAP earnings surprise measure $\left(F \hat{E}_{G A A P}\right)$ is the same as the estimated Street earnings surprise measure $\left(F \hat{E}_{\text {Street }}\right)$ - they are both equal to the difference between $E P S_{G A A P}$ and $F E P S_{\text {Street }}$ in our stylized setting - their corresponding measurement errors are not the same because the true GAAP and Street earnings surprises are different (i.e., $F E_{G A A P}$ $\neq F E_{\text {Street }}$ ). In particular, the measurement error in the GAAP earnings surprise estimate is equal to $\mathrm{E}\left(E P S_{\text {Diff }}\right)$, the expected difference between GAAP and Street EPS. The estimated GAAP earnings surprise coefficient is therefore biased downward and is equal to the following (both before and after the regime shift):

$$
\hat{E} R C_{G A A P}=\frac{\operatorname{cov}\left(F E_{G A A P}, U R\right)}{\operatorname{var}\left(F E_{G A A P}\right)+\operatorname{var}\left(E\left(E P S_{D i f f}\right)\right)}<E R C_{G A A P .}
$$

Overall, the GAAP Expectation Error introduces a downward bias in ERC estimates for GAAP earnings and the bias persists over time. We summarize this discussion in our second proposition below:

\section{Proposition 2: The GAAP Expectation Error induces a downward bias in GAAP ERC, both before and after the regime shift. Thus, the differences between Street and GAAP ERCs are overstated throughout the estimation period.}

The effect of the GAAP Expectation Error is illustrated in Panel B of Figure 1. The dotted line represents a trend in the true unbiased GAAP ERC, and the solid line represents a trend in the estimated GAAP ERC. The GAAP Expectation Error shifts the true unbiased GAAP 
ERC trend line downwards, increasing the observed gap between GAAP and Street ERCs. The effects of the biases induced by both the GAAP Expectation Error and the I/B/E/S Adjustment Error are summarized below:

\begin{tabular}{|l|c|c|}
\hline & Pre-Regime Shift & Post-Regime Shift \\
\hline ERC $_{\text {GAAP }}$ & $\begin{array}{c}\text { GAAP Expectation Error } \\
\text { (Downward Bias) }\end{array}$ & $\begin{array}{c}\text { GAAP Expectation Error } \\
\text { (Downward Bias) }\end{array}$ \\
\hline ERC $_{\text {Street }}$ & $\begin{array}{c}\text { I/B/E/S Adjustment Error } \\
\text { (Downward Bias) }\end{array}$ & \\
\hline
\end{tabular}

Panel C of Figure 1 illustrates the combined effect of the two biases.

\section{Sample and Data}

We derive our sample from the intersection of Compustat, I/B/E/S (detailed files), and CRSP databases for the period spanning 1985 to 2003. Observations are excluded from our sample if the following data are missing: earnings from Compustat; actual and forecasted earnings per share (EPS), earnings announcement dates, and stock prices from I/B/E/S; and stock returns from CRSP.

To ensure that our results are not driven by outliers, we eliminate all observations with absolute $\mathrm{I} / \mathrm{B} / \mathrm{E} / \mathrm{S}$ and GAAP forecast errors greater than $10 \%$ of the stock price, as well as penny stocks with an end-of-quarter share price less than $\$ 1$. Our main sample consists of 188,732 firm-quarter observations for the 1985 to 2003 period. To compare our results with those in Bradshaw and Sloan (2002), we also use a subsample with 112,962 firm-quarter observations that fall into the 1987 to 1997 period.

Similar to prior studies (e.g., Bradshaw and Sloan, 2002) we refer to the actual EPS obtained from I/B/E/S as Street earnings. GAAP EPS is computed as earnings before extraordinary items (Compustat quarterly data item \#8) divided by the number of common shares 
used to calculate diluted EPS (Compustat quarterly data item \#124). ${ }^{10}$ If the number of common shares for diluted EPS is not available, we use the number of common shares to calculate basic EPS (Compustat quarterly data item \#150). ${ }^{11}$ This definition of earnings excludes both extraordinary items and earnings from discontinued operations and is comparable to earnings numbers used in prior studies (e.g., Bradshaw and Sloan, 2002). ${ }^{12}$ Both GAAP and I/B/E/S EPS are scaled by stock price at the beginning of the quarter and converted to the same split-adjusted basis.

In the returns-earnings regression, we measure stock returns as the three-day buy-andhold return around quarterly earnings announcement dates minus the corresponding valueweighted market return. The resulting returns are winsorized at the $1^{\text {st }}$ and the $99^{\text {th }}$ percentiles within each sample year. ${ }^{13}$ Following Brown (2001), we use the last EPS forecast within the 90 days before the quarterly earnings announcement date to proxy for the market's expectation. ${ }^{14}$ Accordingly, we define GAAP (Street) earnings surprises (hereafter, GAAP and Street forecast errors) as the difference between GAAP (I/B/E/S) EPS and the most recent analyst forecast, both scaled by the stock price at the beginning of the quarter. We obtain earnings announcement dates from $\mathrm{I} / \mathrm{B} / \mathrm{E} / \mathrm{S}$.

\footnotetext{
${ }^{10}$ Our empirical results (presented in Sections 3.2 and 3.3) are robust to using operating earnings (as in Bhattacharya et al., 2003) instead of earnings before extraordinary items. Total operating earnings is computed as GAAP basic earnings per share from operations (Compustat quarterly data item \#177) multiplied by the number of basic shares outstanding (Compustat quarterly data item \#15).

${ }^{11} \mathrm{I} / \mathrm{B} / \mathrm{E} / \mathrm{S}$ ' EPS value is adjusted for dilution if the corresponding GAAP EPS is calculated on a diluted basis.

${ }^{12}$ Consistent with our definition of $E P S_{G A A P}, \mathrm{I} / \mathrm{B} / \mathrm{E} / \mathrm{S}$ ' definition of earnings per share also excludes extraordinary items and earnings from discontinued operations (The I/B/E/S Glossary, 2001).

${ }^{13}$ None of our results are sensitive to winsorization of returns or other variables.

${ }^{14}$ If several earnings forecasts were issued on that particular date, we use the median value as an estimate. We choose to employ the most recent forecast of a single individual analyst to improve the accuracy and timeliness of the forecast (O'Brien, 1988). Our results are robust to using the most recent consensus forecasts from $\mathrm{I} / \mathrm{B} / \mathrm{E} / \mathrm{S}$ summary files.
} 


\section{Empirical Analysis and Results}

\subsection{Increased Reaction to Street (over GAAP) Earnings}

We begin our analysis by replicating the documented increased divergence pattern in the ERC for Street and GAAP earnings. Similar to prior studies, we measure ERCs as the slope coefficients from yearly cross-sectional regressions of short-window market-adjusted returns on each of the two alternative forecast error measures. ${ }^{15}$ As defined before, $F E_{\text {Street }}\left(F E_{G A A P}\right)$ is the difference between I/B/E/S actual EPS (GAAP EPS) and forecasted EPS. Figure 2 plots the time series of ERCs based on these two alternative earnings surprise $(F E)$ measures, which we refer to as Street ERC $\left(E R C_{\text {Street }}\right)$ and GAAP ERC $\left(E R C_{G A A P}\right)$. Consistent with Bradshaw and Sloan (2002), Figure 2 shows a clear increase in the difference between the two ERC estimates, which begins in the early 1990s.

To complement the descriptive evidence presented in Figure 2, we follow Bradshaw and Sloan (2002) and estimate GAAP and Street ERCs for the pooled sample. The temporal changes in ERCs are captured by an interaction term between forecast errors and a time trend variable. The results are reported in Table 1. The first three columns correspond to analyses based on the full sample period (i.e., from 1985 to 2003). To allow for a direct comparison with prior studies, we also report results for the 1985 to 1997 subperiod in the last three columns. ${ }^{16}$ Overall, results for the two sample periods are qualitatively and statistically similar; we therefore focus our discussion on the full sample results.

Table 1, Panel A reports the coefficient estimates for Model I, which includes the time trend variable $Y E A R$. The coefficients on the interaction terms $F E^{*} Y E A R$ are positive and

\footnotetext{
${ }^{15}$ Bradshaw and Sloan (2002) use long-window stock returns in their analyses, which they define as the buy-andhold returns from the two days after the last quarterly announcement through the day after the current-period earnings announcement. As a sensitivity check, we also compute long-window stock returns and report these results in Section 4.2.

${ }^{16}$ Bradshaw and Sloan's (2002) sample spans 1985 to 1997. Abarbanell and Lehavy's (2006) sample spans 1985 to 1998.
} 
significant for both Street and GAAP forecast errors. Moreover, the difference between the two interaction terms reported in column 3 is also significantly positive. These results suggest that while both earnings measures appear to have become more informative over the sample period, the increase is significantly higher for Street earnings.

Following Bradshaw and Sloan (2002), in Model II we replace the continuous time trend measure YEAR with the indicator variable POST91, which takes the value of zero for the 1985 to 1991 subperiod. The results, reported in Panel B of Table 1, are qualitatively similar to those presented in Panel A. In particular, we find positive and significant coefficients on the interaction term FE*POST91 for both earnings measures, suggesting that investors view both earnings measures as more informative in the second half of the sample period. Further, the positive coefficient on the difference between the interaction terms suggests that the increase is significantly more pronounced for Street earnings, consistent with the apparent divergence pattern reflected in Figure 2. Overall, the results in this section are consistent with the market increasing its reliance, or fixation, on Street (over GAAP) earnings over the past decade, as documented by Bradshaw and Sloan (2002). In the subsequent sections, we explore the extent to which the documented divergence between the two estimated ERCs is an artifact of measurement error biases, rather than a reflection of increased reliance or fixation on Street earnings.

\subsection{Decomposing Earnings Response Coefficients (ERCs)}

In this section, we provide preliminary evidence on the importance of the $I / B / E / S$ Adjustment Error and the I/B/E/S regime shift (that corrects the error) in producing a divergence pattern between Street and GAAP ERCs. Recall that prior to I/B/E/S' regime shift, the estimated Street 
ERC is equal to $\frac{\operatorname{cov}\left(F E_{\text {Street }}, U R\right)+\operatorname{cov}\left(E P S_{\text {Diff }}, U R\right)}{\operatorname{var}\left(F E_{\text {Street }}\right)+\operatorname{var}\left(E P S_{\text {Diff }}\right)}$, which is smaller than the true Street ERC (i.e., $\left.\frac{\operatorname{cov}\left(F E_{\text {Street }}, U R\right)}{\operatorname{var}\left(F E_{\text {Street }}\right)}\right)$. If the elimination of the downward bias is responsible for the ERC divergence pattern, then we should observe a downward shift in the variance of the Street forecast error around the time of the regime shift. ${ }^{17}$ Accordingly, we separately study the temporal changes in ERCs' two components: (1) the numerator - the covariance between the three-day abnormal return around a quarterly earnings announcement and the $\mathrm{I} / \mathrm{B} / \mathrm{E} / \mathrm{S}$ or GAAP forecast error, and (2) the denominator - the variance of the forecast error.

We begin our analysis by plotting the forecast errors-returns covariances (hereafter, Street and GAAP covariances) and the inverse of the forecast error variances (hereafter, the inverse of Street and GAAP variances) for each year in our sample period. Note that we present the inverse of the variance instead of the variance to facilitate direct comparison with the ERC figures. Figure 3, Panel A plots the inverse of Street and GAAP variances. The pattern in the inverse variances is consistent with the $I / B / E / S$ Adjustment Error being an important driver of the ERC divergence pattern. Specifically, while the inverse of Street variance has increased substantially over the sample period (the trend is significantly positive), the corresponding GAAP curve has stayed relatively flat over time (the trend is not significant). More importantly, there appears to be a clear upward shift in the inverse of Street variance in the 1990s (as opposed to a gradual upward trend), which coincides with the regime shift. Overall, the divergence pattern in the inverse variances mirrors the divergence pattern in ERCs.

\footnotetext{
${ }^{17}$ The covariance portion of the bias (which affects the numerator of the estimated Street ERC) cannot be responsible for the divergence pattern because, holding the variance component constant, the elimination of the measurement error in the estimated Street earnings surprise would reduce the numerator of the estimated Street ERC, and hence decrease the estimated Street ERC.
} 
Figure 3, Panel B plots the Street and GAAP covariances. Panel B shows that the GAAP covariance is consistently higher than the Street covariance during the entire period, suggesting that a value-relevant component is included in GAAP earnings, but excluded from Street earnings (i.e., excluded by $\mathrm{I} / \mathrm{B} / \mathrm{E} / \mathrm{S}$ ). Further, we find a mild increase in the divergence between the two covariances that is in the opposite direction of the ERC differences.

Overall, our evidence suggests that the increased ERC divergence is solely attributable to a corresponding increased divergence in the difference between Street and GAAP forecast error variances, which appears to be in part an artifact of the $\mathrm{I} / \mathrm{B} / \mathrm{E} / \mathrm{S}$ regime shift. We find no significant contemporaneous increase in the covariance difference. Taken together, these results suggest that the documented ERC divergence pattern is due at least in part to decreased noisiness of Street forecast errors resulting from better alignment between the definitions of actual and forecasted earnings.

\subsection{Reverse Earnings Response Coefficients (Reverse ERCs)}

In this section, we extend the preliminary ERC decomposition evidence and employ a commonly used remedy for "errors in variables" problems in unexpected earnings, namely, reverse regression analysis (e.g., Beaver et al., 1987; Collins and Kothari, 1989). Specifically, we regress earnings surprise measures for GAAP and Street earnings on unexpected returns. The slope coefficient from the reverse regression, which we refer to as reverse ERC ( $\operatorname{RevERC})$, is equal to:

$$
\operatorname{RevERC}=\frac{\operatorname{cov}(F E, U R)}{\operatorname{var}(U R)},
$$

where $F E$ is unexpected earnings and $U R$ is the unexpected return associated with the earnings shock. The reciprocal of the reverse ERC is an upward bound estimate for the original ERC. 
Assuming a stochastic relationship between earnings surprises and stock returns, that is, $U R=\alpha+E R C^{*} F E+\varepsilon$, the reciprocal of the reverse ERC is equal to: ${ }^{18}$

$$
\frac{1}{\operatorname{Rev} \hat{E} R C}=E R C+\frac{\operatorname{var}(\varepsilon)}{\operatorname{cov}(F E, U R)}>E R C .
$$

The above expression is free of the bias induced by classic measurement error in earnings surprises, that is, the error that is uncorrelated with $U R$. When measurement error in $F E$ is correlated with $U R$, it is more difficult to interpret the slope coefficient from the reverse earnings-returns regression. While the GAAP Expectation Error represents the first type of measurement error that is uncorrelated with the dependent variable, the $I / B / E / S$ Adjustment Error corresponds to the second, more complicated, case. We provide a detailed discussion of the properties of reverse ERCs for both cases in the Appendix. Specifically, we show that under certain reasonable restrictions, the reciprocals of the reverse ERCs are biased in the direction of finding an increased divergence pattern, that is, the potential bias in the reverse ERCs works against finding an insignificant reverse ERC difference.

To estimate the reverse ERCs, we employ procedures that parallel the original analysis in Section 3.1. Specifically, reverse ERCs are the slope coefficients from the yearly cross-sectional regressions of the two alternative earnings surprise measures, Street and GAAP, on shortwindow market-adjusted returns around the quarterly earnings announcements dates. The timeseries plots of the estimated reverse ERCs and the reciprocals of the reverse ERCs (hereafter, reciprocal reverse ERCs) for GAAP and Street EPS are plotted in Figure 4, Panels A and B. These two graphs stand in a stark contrast to the original ERCs graph presented in Figure 2. Specifically, we do not observe a drastic divergence pattern between the reverse Street and

\footnotetext{
${ }^{18}$ Briefly, the expression for the reverse ERC is derived from: $\operatorname{Rev} \hat{E} R C=\operatorname{cov}(F E, U R) / \operatorname{var}(U R)$ $=\operatorname{cov}(F E, U R) /\left(E R C^{2} \operatorname{var}(F E)+\operatorname{var}(\varepsilon)\right)=\operatorname{cov}(F E, U R) /(E R C \operatorname{cov}(F E, U R)+\operatorname{var}(\varepsilon))$.
} 
GAAP ERCs. In fact, the difference between the two time-trend slopes (i.e., -0.001 for both the reverse Street and GAAP ERCs) is insignificantly different from zero. While we do observe a small increase in the difference between the reciprocal reverse ERCs in the more recent years, there is no clear divergence prior to 1998. This pattern differs substantially from the original ERC divergence beginning in the early 1990s, as reported in prior studies and in Section 3.1 of this paper. Further, in more recent years, the magnitude of the reciprocal reverse ERC divergence is relatively small compared to that found in the original ERCs. ${ }^{19}$ To facilitate comparison between the original ERCs and the reciprocal reverse ERCs, we graph both sets of ERC series in Figure 4, Panel C. The original and reciprocal ERC curves are brought to the same scale based on the original ERC values, that is, the reciprocal ERCs are deflated by the corresponding original ERC values for the first year (i.e., 1985). Informal inspection of this figure yields the following two observations: (1) the reciprocal reverse ERC divergence, if any, appears to be substantially smaller than the previously documented ERC divergence, and (2) the difference between the two reciprocal reverse ERCs at any point in time is smaller than its original counterpart. Taken together, the descriptive evidence from Figure 4, Panel C is consistent with both the $I / B / E / S$ Adjustment Error and the GAAP Expectation Error being important drivers of the documented ERC divergence pattern.

To complement the descriptive evidence discussed above, we perform regression analyses similar to those reported in Section 3.1 for the original returns-earnings regressions. Specifically, we estimate pooled reverse earnings-returns regressions for both the full sample and the Bradshaw and Sloan (2002) 1985 to 1997 subsample with interaction dummies capturing

\footnotetext{
${ }^{19}$ From Figures 2 and 4, we note that while the magnitudes of the reciprocal reverse ERCs (Panel B, Figure 4) are substantially larger than their original counterparts (Figure 2), they are in line with the numbers reported in prior studies (e.g., Basu, 1997). As noted earlier, the reciprocal reverse ERCs are the upper bound of the true ERCs, where the exact magnitude of the bias depends upon the R-squared of the returns-earnings regression. In other words, when a large extent of the returns variance is unexplained by earnings surprises (i.e., low R-squared), the reciprocal reverse ERCs would be substantially different from the original ERCs.
} 
time trends in reverse ERCs. Table 2 reports the results from the two models: Model I (II) includes an interaction term with the continuous (dichotomous) time-trend measure YEAR (POST91). The main variable of interest, as in the original ERC regressions, is the interaction term between abnormal returns and the time trend variable. In contrast to the results from the original ERC regression (where the difference between the coefficients on the interaction term is positive and significant), the difference between the coefficients on the interaction term in Models I and II is insignificantly different from zero in the reverse regressions, for both the full sample period and the 1985 to 1997 subperiod (as reported in the third column, in Panel A and Panel B). This result confirms the descriptive evidence presented in Figure 4, suggesting that the significant upward trend in the ERC difference, documented in Section 3.1, Bradshaw and Sloan (2002) and Abarbanell and Lehavy (2006), is driven primarily by the $I / B / E / S$ Adjustment Error, an artifact of the I/B/E/S regime shift. In other words, the inference about the market's increased reliance or fixation on Street earnings is based on the spuriously overstated upward trend in Street ERC, as a result of the $I / B / E / S$ Adjustment Error. ${ }^{20}$

Recall that the $I / B / E / S$ Adjustment Error induces a significant upward trend in the ERC difference; the GAAP Expectation Error simply overstates the average ERC difference given GAAP EPS differs from Street EPS. The analyses presented in Table 2 shed light primarily on the importance of the $I / B / E / S$ Adjustment Error. With respect to the GAAP Expectation Error, it is more difficult to empirically assess the extent to which the magnitude and the significance of the ERC difference are influenced by a downward-biased estimate of GAAP ERC. The difficulty

\footnotetext{
${ }^{20}$ Changes in accounting standards in the early 1990s are a potential alternative explanation for the reverse regression results. Specifically, if the new accounting standards move towards fair-value accounting and thereby create more transitory items in GAAP earnings, estimating reverse earnings-returns regressions would remove not only the measurement error in forecast errors, but also the variance of the transitory component embedded in GAAP earnings. However, examining the accounting standards that became effective in the early 1990s, the first standard that may have a significant impact on GAAP earnings, SFAS 121, became effective in 1995, which is after the regime shift period. Moreover, such accounting changes would increase the variance of GAAP earnings without necessarily affecting the variance of Street earnings, an opposite pattern to the one observed in our ERC decomposition results.
} 
is due to the fact that Street earnings likely exclude certain transitory (or less persistent) components from GAAP earnings, which, even absent the downward bias, can lead to a significant difference between GAAP and Street ERCs. Nevertheless, we attempt to provide some descriptive evidence on this issue by estimating original and reverse ERCs separately for the pooled sample and by year. To parse out the effect of the $I / B / E / S$ Adjustment Error, we focus our analysis on the post-regime shift subperiod, 1993 to 2003. We report the results in Table 3. The left (right) panel reports the ERC (reverse ERC) difference from the original (reverse) regressions. While we continue to find a significant difference in the reverse ERCs for the pooled sample, the yearly reverse ERCs differences are significant in only five out of the eleven years. ${ }^{21}$ In contrast, the original ERCs differences are significant in all eleven years. Moreover, the significant reverse ERC differences are concentrated in the recent years, with relatively large differences between GAAP and Street earnings. Overall, this result provides descriptive evidence consistent with the GAAP Expectation Error being a significant driver of the average ERC difference.

Note that the results presented in Sections 3.2 and 3.3 are subject to the following caveats. First, our results for the $I / B / E / S$ Adjustment Error are applicable only to those studies that use I/B/E/S earnings to proxy for Street earnings, not to those studies that use actual pro forma numbers from press releases, as the latter are not subject to the $I / B / E / S$ Adjustment Error. Second, while our results are consistent with measurement error being a primary driver of the documented increase in ERC differences, we acknowledge that other (non-mutually exclusive) explanations (e.g., increased frequency of negative special items; change in accounting standards) may also play a role.

\footnotetext{
${ }^{21}$ These results should be interpreted with caution because estimating reverse ERC for GAAP earnings removes not only the GAAP Expectation Error, but also part of the transitory GAAP component. Accordingly, the reduction in the magnitude of the difference between GAAP and Street ERCs is partly due to the transitory nature of earnings components excluded from the Street definition.
} 


\subsection{Implications for Future Research: Generalized Expectation Error}

In our formalized framework, we focus on the properties of two specific measurement errors, the $I / B / E / S$ Adjustment Error and the GAAP Expectation Error. The $I / B / E / S$ Adjustment Error is mainly relevant to those studies that use $\mathrm{I} / \mathrm{B} / \mathrm{E} / \mathrm{S}$ forecast errors to proxy for Street earnings surprises and examine the temporal trend in the information content of Street earnings over the 1990s. The GAAP Expectation Error, on the other hand, can be generalized to other non-GAAP earnings settings and hence has broader implications for studies that examine the information content of any non-GAAP earnings figure, such as pro-forma earnings (e.g., Bhattacharya et al., 2003) or Standard and Poor's “operating” earnings (e.g., Brown and Sivakumar, 2003). In this subsection, we discuss the implications of our findings for assessing the information content of other non-GAAP earnings figures.

Recall that the GAAP Expectation Error is an error in the expected earnings component of GAAP earnings surprises. This "expectation error" arises because, absent a GAAP earnings forecast, researchers often resort to a second-best solution—using analyst's forecasts (provided by $\mathrm{I} / \mathrm{B} / \mathrm{E} / \mathrm{S}$ or other forecast data providers) to proxy for GAAP earnings expectations. The same type of measurement error and corresponding downward bias in ERC will accompany any GAAP or non-GAAP earnings surprise proxy as long as the definition of realized earnings (GAAP or non-GAAP) deviates from the definition of forecasted earnings provided by $\mathrm{I} / \mathrm{B} / \mathrm{E} / \mathrm{S}$ (or other commercial forecast data providers). To illustrate the properties of this generalized expectation error and the bias it introduces in ERC, we follow a framework that is similar to that presented in Section 1 and use pro-forma earnings $\left(E P S_{P F}\right)$ as an example of non-GAAP earnings.

We first define the true pro-forma earnings surprise as follows: 
True Pro-Forma Earnings Surprise: $\quad F E_{P F} \quad=\quad E P S_{P F}-\mathrm{E}\left(E P S_{P F}\right)$, where $E P S_{P F}=$ Realized Pro-Forma Earnings $\mathrm{E}\left(E P S_{P F}\right)=$ Expected Pro-Forma Earnings.

We assume that $\mathrm{I} / \mathrm{B} / \mathrm{E} / \mathrm{S}$ forecasts $\left(F E P S_{I / B / E / S}\right)$ are not a perfect proxy for pro-forma earnings expectations (i.e., $\left.F E P S_{I / B / E / S} \neq \mathrm{E}\left(E P S_{P R}\right)\right)$, that is, the definition of analyst-reported $\mathrm{I} / \mathrm{B} / \mathrm{E} / \mathrm{S}$ earnings $\left(E P S_{I / B / E / S}\right)$ is not always the same as the definition of manager-reported pro-forma earnings $\left(E P S_{P F}\right)$, which is consistent with Bhattacharya et al. (2003). Further, we define the difference between $E P S_{P F}$ and $E P S_{I / B / E / S}$ as $E P S_{D i f f_{-} P F}$. We summarize our model's assumptions, the derivation of the estimated pro-forma earnings surprise, and the corresponding measurement error as follows:

Assumptions:

Empirical proxy for $E P S_{P F} \quad=$ Pro-forma earnings (from earnings releases) Empirical proxy for $\mathrm{E}\left(E P S_{P F}\right)=\mathrm{I} / \mathrm{B} / \mathrm{E} / \mathrm{S}$ ' forecasted earnings $=F E P S_{I / B / E / S}$ $F E P S_{I / B / E / S} \neq \mathrm{E}\left(E P S_{P R}\right)$

Estimated Pro-Forma Earnings Surprise: $F \hat{E}_{P F}=E P S_{P F}-F E P S_{I / B / E / S}$

$$
\begin{array}{ll}
= & E P S_{P F}-\left[\mathrm{E}\left(E P S_{P F}\right)-\mathrm{E}\left(E P S_{\text {Diff_PF }_{-}}\right)\right] \\
= & F E_{P F}+\mathrm{E}\left(E P S_{\text {Diff_PF }_{P}}\right) \\
= & F E_{P F}+\text { Measurement Error. }
\end{array}
$$

Note that the measurement error of the estimated pro-forma earnings surprise measure is very similar to that of the estimated GAAP earnings surprise. Its magnitude is likely to be less pronounced, however, because the definition of $\mathrm{I} / \mathrm{B} / \mathrm{E} / \mathrm{S}$ forecasts is generally more closely aligned with the definition of pro-forma earnings than that of GAAP earnings. In other words, the expected difference between pro-forma and I/B/E/S EPS is likely smaller that that between GAAP and I/B/E/S EPS. Therefore, similar to the estimated GAAP ERC, the estimated proforma ERC is also biased downward, but to a lesser extent:

$$
\hat{E} R C_{P F}=\frac{\operatorname{cov}\left(F E_{P F}, U R\right)}{\operatorname{var}\left(F E_{P F}\right)+\operatorname{var}\left(E\left(E P S_{D_{i f f_{-} P F}}\right)\right)}<E R C_{P F} .
$$


Again, the above example for pro-forma earnings can be generalized to any non-GAAP (and non-I/B/E/S) earnings figure. While it is not easy to derive a perfect expectation proxy for any GAAP or non-GAAP earnings specification, exploring other "second-best" expectation proxies (e.g., a modified I/B/E/S forecast that incorporates an expectation of the excluded items) would be a fruitful avenue for future research. In particular, given our empirical findings future research may consider estimating reverse earnings-returns regressions to assess the measurement error bias of alternative earnings surprise proxies.

\section{Sensitivity Analysis}

\subsection{Excluding Extreme Earnings Differences}

A recent study by Abarbanell and Lehavy (2006) finds that the increased divergence between Street and GAAP ERCs is driven primarily by a small number of extreme observations with large mean differences between GAAP and Street forecast errors. Prima facie, this empirical result is consistent with the measurement error hypotheses proposed in our paper. Recall that the expressions for the measurement error bias introduced into both GAAP and Street ERCs depend on the difference between GAAP and Street EPS. It is possible that excluding observations with extreme observed forecast error differences coincidentally eliminates observations with large true EPS differences, which would mitigate (or eliminate) the measurement error bias. We explore this possibility by removing the "extreme negative tail of the earnings difference distribution," defined as the bottom quintile of the negative earnings difference observations in Abarbanell and Lehavy. ${ }^{22}$ We find that while the resulting pattern of increased divergence in

\footnotetext{
${ }^{22}$ Specifically, Abarbanell and Lehavy first sort all observations into three groups: zero, positive and negative earnings differences; they then rank the earnings differences within the positive group and within the negative group, separately, into quintiles. We would like to note that we find a lower incidence of zero differences in our sample than that reported in Abarbanell and Lehavy, probably because of differences in our measures of GAAP EPS. In particular, while we calculate GAAP EPS by dividing income before extraordinary item by the weighted
} 
ERCs becomes less pronounced, the upward trend in the ERC difference is still statistically significant. Additionally, the ERC decomposition and reverse regression analyses yield results that are qualitatively similar to those obtained for the full sample. In particular, ERC divergence is driven entirely by changes in the variance component of ERC, whereas the reverse regressions do not indicate increased divergence in ERCs. Overall, our results suggest that the measurement error bias is not eliminated by excluding extreme observations.

As discussed previously, while our conclusions are similar to those of Abarbanell and Lehavy (2006), our methodology is substantially different in at least two respects. First, while Abarbanell and Lehavy (2006) present important empirical results that show that extreme observations drive the divergence in ERCs, we explore the underlying cause of the observed divergence. ${ }^{23}$ Second, Abarbanell and Lehavy (2006) provide evidence on the effect of excluding these extreme observations on the first moment of the distribution (i.e., the mean effect) whereas our analysis demonstrates the importance of analyzing the second moment of the distribution (i.e., the variance effect).

\subsection{Alternative Return Window}

Our main ERC analysis is based on short-window returns around earnings announcement dates. However, some of the evidence documented in prior literature on the differential market response to earnings in $\mathrm{I} / \mathrm{B} / \mathrm{E} / \mathrm{S}$ and GAAP definitions is based on long-window returns. For

average number of shares outstanding (see footnote 10), they use the Data 9 or Data 19 EPS figures from Compustat, which are generally accurate to the second decimal place. When we follow their approach to calculate GAAP EPS, we find very similar results. We therefore construct the negative earnings difference portfolio (i.e., the Portfolio 1 reported in Table 2 of Abarbanell and Lehavy) using their measure of GAAP EPS. In addition, we perform two alternative sensitivity tests by removing the extreme $5 \%$ or $10 \%$ observations on the left tail of the entire earnings difference distribution. Results from the three sensitivity tests are qualitatively and statistically similar.

${ }^{23}$ Also, by excluding observations with the largest differences between observed Street and GAAP forecast errors, Abarbanell and Lehavy may omit firms that have valid reasons for excluding certain (less persistent) items, introducing potential sample selection bias into their research design. 
instance, Bradshaw and Sloan (2002) use long-window stock returns for the interval beginning two days after the last quarterly earnings announcement date and ending the day after the current quarterly announcement date. We therefore investigate whether our results are robust to using long-window association tests between market-adjusted stock returns and the different earnings surprise metrics. The analyses (unreported) show that our results are qualitatively and statistically similar when long-term quarterly returns are used to compute ERCs, both for the original and the reverse earnings-returns regressions.

One of the benefits of using a long interval for returns estimation arises from the fact that longer windows allow one to capture the effects of any earnings pre-announcements. For example, Skinner (1997) finds that firms with negative earnings surprises are more likely to preannounce earnings and to do so within two weeks of the fiscal quarter-end. Note, however, that the main thrust of our analysis is based on the cross-sectional comparison between variables estimated with $\mathrm{I} / \mathrm{B} / \mathrm{E} / \mathrm{S}$ versus GAAP earnings. Our emphasis on the relative magnitude of $\mathrm{I} / \mathrm{B} / \mathrm{E} / \mathrm{S}$ earnings response coefficients, forecast error means, and variances, compared to the corresponding GAAP estimates, naturally controls for many contemporaneous confounding factors.

\subsection{Sampling Error}

The distribution of observations across our sample period is not uniform: the later years contain substantially more observations with the data necessary for our analyses. For example, the latest year in our sample (2003) has 11,496 observations, while the first year of the "shift" (1990) has 7,424 observations. In general, the pattern in the yearly composition for our sample is similar to 
the gradual increase in the number of observations over time observed in prior studies with similar data requirements (e.g., Abarbanell and Lehavy, 2006). ${ }^{24}$

The change in the number of observations across years suggests an alternative explanation for the observed trend in the variances. Namely, the temporal reduction in sampling error resulting from the significant increase in the number of observations in our sample can lead to a decrease in the estimated variances for $\mathrm{I} / \mathrm{B} / \mathrm{E} / \mathrm{S}$-based forecast errors. To rule out this potential explanation, we randomly select an equal number of observations for each year of our sample, starting with 1988 . We use 5,000 observations as the cutoff for each year of the sample. All our results are robust to this sensitivity check.

Further, to ensure that the changes in the original and reverse ERCs are not caused by changes in sample composition, we conduct additional robustness tests for the 1989 to 1998 time period. ${ }^{25}$ We replicate our analyses including only those firms that are present in each quarter of these ten years. The restricted sample consists of 310 firms and 12,400 firm-quarter observations. All our results, including the original ERC divergence pattern, hold for this sample with constant firm composition.

\section{Conclusions}

We investigate whether the dramatic increase in the difference between the ERCs for GAAP and Street earnings documented in prior studies - a result that has sparked a debate about increased market fixation on Street earnings - is driven in part by measurement error in earnings surprise

\footnotetext{
${ }^{24}$ Bradshaw and Sloan (2002) do not report observations in their study by year, and hence we cannot directly compare our sample size by year. We note that the number of firm-quarter observations in our sample from 1985 to 1997 (the sample period in their study) is 112,962, which is reasonably similar to that in Bradshaw and Sloan (98,647 firm-quarter observations).

${ }^{25}$ Requiring a constant sample composition for the entire sample period (i.e., 1985 to 2003) results in a prohibitively small number of observations, and we therefore conduct the robustness test using a shorter sample period (i.e., 19891998). We also construct an alternative sample by retaining firms that are present in 16 (64) out of 19 years (76 quarters) in the $1985-2003$ period and we find qualitatively and statistically similar results.
} 
proxies. Specifically, we explore two biases, (1) a downward bias in Street ERC arising from an inconsistency between $\mathrm{I} / \mathrm{B} / \mathrm{E} / \mathrm{S}$ ' definition of actual and forecasted earnings (i.e., $I / B / E / S$ Adjustment Error), in the early 1990s, before I/B/E/S undertook a regime shift to correct the error, and (2) a downward bias in GAAP ERC arising from using $\mathrm{I} / \mathrm{B} / \mathrm{E} / \mathrm{S}$ forecasts to proxy for GAAP earnings expectations (i.e., GAAP Expectation Error).

By decomposing ERCs into their covariance and variance components, we first establish that the increased difference between Street and GAAP ERCs is driven solely by the variance effect. This result, along with an apparent downward shift in the variance of Street forecast errors in the early 1990s, suggests that the ERC divergence pattern is at least partially attributable to the correction of the $I / B / E / S$ Adjustment Error. Results from reverse earnings-returns regression analysis provide further support for this finding. In particular, we do not find a significant increase in the difference between the reverse GAAP and Street ERCs over our sample period. Further, the difference in the reverse ERCs (from the reverse regressions) is significant in only five out of the eleven years after the regime shift (1993 to 2003). Overall, our results suggest that the $I / B / E / S$ Adjustment Error (along with the $\mathrm{I} / \mathrm{B} / \mathrm{E} / \mathrm{S}$ regime shift that corrects the error) and the GAAP Expectation Error play an important role in the ERC divergence pattern. Thus, future research on GAAP versus Street earnings should take into consideration the potential biases arising from measurement errors in GAAP and Street earnings surprises, and should draw inferences from the conventional analysis of GAAP and Street ERCs with caution. 


\section{Appendix}

In the Appendix, we explore the properties of the estimated ERCs from the reverse GAAP and Street earnings-returns regressions in a stylized two-period setting. Specifically, we determine conditions under which the reverse regressions provide unambiguous inferences about the ERC divergence trends. We use the same notation as in Section 1, as summarized in the following table:

\begin{tabular}{|c|c|}
\hline$E_{P S} S_{G A P}$ and $E P S_{\text {Street }}$ & GAAP and Street earnings, respectively \\
\hline $\boldsymbol{E P S}_{\text {Diff }}$ & $\mathrm{EPS}_{\mathrm{GAAP}}-\mathrm{EPS}_{\text {Street }}$ \\
\hline FEPS $_{\text {Street }}$ & I/B/E/S earnings forecasts (Street earnings expectations) \\
\hline$F E_{G A A P}$ and $F E_{\text {Street }}$ & GAAP and Street forecast errors, respectively \\
\hline$F E_{\text {Diff }}$ & $\mathrm{FE}_{\mathrm{GAAP}}-\mathrm{FE}_{\text {Street }}$ \\
\hline$E R C_{G A A P}$ and $E R C_{\text {Street }}$ & Unbiased GAAP and Street ERCs, respectively \\
\hline 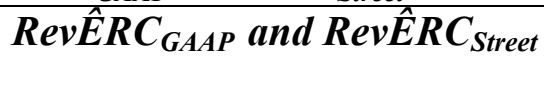 & $\begin{array}{l}\text { Estimated reverse GAAP and Street ERCs from reverse } \\
\text { earnings-returns regressions, respectively }\end{array}$ \\
\hline
\end{tabular}

As in Section 1, we assume that $\mathrm{I} / \mathrm{B} / \mathrm{E} / \mathrm{S}$ forecasts are perfect proxies for Street earnings expectations at all times (i.e., $\left.F E P S_{\text {Street }}=\mathrm{E}\left(E P S_{\text {Street }}\right)\right)$. Before the regime shift, I/B/E/S actual earnings correspond to $E P S_{G A A P}(\mathrm{GAAP} E P S)$ as a result of the "I/B/E/S Adjustment Error" (i.e., misalignment between $\mathrm{I} / \mathrm{B} / \mathrm{E} / \mathrm{S}$ actual and forecasted earnings). After the regime shift that corrects for the misalignment, I/B/E/S actual earnings perfectly reflect Street EPS. Additionally, we assume the following stochastic relationship between stock returns and the two alternative measures of earnings surprises: ${ }^{26}$

GAAP earnings surprises: $\quad U R=\alpha+E R C_{G A A P} * F E_{G A A P}+\varepsilon_{1}$

Street earnings surprises: $\quad U R=\alpha+E R C_{\text {Street }} * F E_{\text {Street }}+\varepsilon_{2}$.

In the presence of "I/B/E/S Adjustment Error" and "GAAP Expectation Error," the slope coefficients from the reverse regressions of earnings surprise proxies on returns take the

\footnotetext{
${ }^{26}$ For ease of exposition, we do not distinguish between error terms for the sub-periods before and after I/B/E/S' regime shift in Table A1. However, Figure A1 and subsequent discussion reflect a possibility that the error terms may change over time.
} 
following forms in the first period (prior to $\mathrm{I} / \mathrm{B} / \mathrm{E} / \mathrm{S}$ ' regime shift) and the second period (after the regime shift):

Table A1. Estimates for reverse ERCs

\begin{tabular}{|c|c|c|}
\hline (a) & $\begin{array}{c}\text { Period 1: } \\
\text { Before I/B/E/S' "Regime Shift" }\end{array}$ & $\begin{array}{c}\text { Period 2: } \\
\text { After I/B/E/S" } \\
\text { "Regime Shift" }\end{array}$ \\
\hline \multirow{2}{*}{ 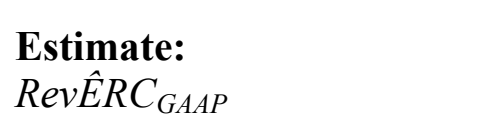 } & 1 & 1 \\
\hline & $\overline{E R C_{G A A P}+A 1}$ & $\overline{E R C_{G A A P}+A 1}$ \\
\hline $\begin{array}{l}\text { Bias: } \\
\left(\operatorname{Rev} \hat{E} R C_{G A A P}\right)^{-1}-E R C_{G A A P}\end{array}$ & A1 $>0$ & A1 $>0$ \\
\hline Estimate: & 1 & 1 \\
\hline 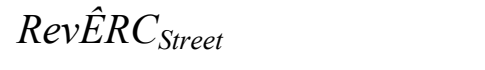 & ${\overline{E R C_{\text {Street }}+A 2}}^{+D}$ & $\overline{E R C_{\text {Street }}+A 2}$ \\
\hline $\begin{array}{l}\text { Bias: } \\
\left(\operatorname{Rev} \hat{E} R C_{\text {Street }}\right)^{-1}-E R C_{\text {Street }}\end{array}$ & $\frac{A 2-B^{*}\left(A 2+E R C_{\text {Street }}\right) * E R C_{\text {Street }}}{1+B^{*}\left(E R C_{\text {Street }}+A 2\right)} \equiv X$ & A2 $>0$ \\
\hline Sources of Bias: & $\begin{aligned} A 1 & =\operatorname{var}\left(\varepsilon_{1}\right) / \operatorname{cov}\left(F E_{G A A P},\right. \\
A 2 & =\operatorname{var}\left(\varepsilon_{2}\right) / \operatorname{cov}\left(F E_{\text {Street }},\right. \\
B & =\operatorname{cov}\left(F E_{\text {Diff }}, U R\right) / \operatorname{var}(\end{aligned}$ & $\begin{array}{l}R) ; \\
R) ; \\
R)\end{array}$ \\
\hline
\end{tabular}

As we discuss in Section 1, the estimated reverse ERCs $\left(\operatorname{Rev} \hat{E} R C_{\text {Street }}\right.$ and $\left.\operatorname{RevER} C_{G A A P}\right)$ are not influenced by the classic measurement error in earnings surprises. However, they are not free of bias, i.e., the reciprocals of reverse ERCs still deviate from the "true" unbiased ERCs. In other words, only when both earnings surprises and returns are measured without error (i.e., when the relationship between earnings surprises and returns is deterministic) are the true ERCs equal to the reciprocals of the reverse ERCs.

There are two sources of bias that are embedded in the expressions in Table A1. The first source of bias stems from the error term $\varepsilon$, which captures the measurement error in returns. We refer to this bias as the "error-term bias"; it has a downward direction in both $\operatorname{RevER} R C_{G A A P}$ and $R e v \hat{E} R C_{\text {Street }}$ in both periods. In Table A1, we denote this bias component as "A1" for GAAP ERC and as "A2" for Street ERC. The second source of bias, referred to as the "I/B/E/S bias," 
affects only $\operatorname{Rev} \hat{E} R C_{\text {Street }}$ in the first period. This bias component, denoted as "B" in Table A1, is related to the $I / B / E / S$ Adjustment Error that we discuss in Section 1. Recall that the measurement error in the Street earnings surprise proxy is equal to $E P S_{\text {Diff }}$ before the $\mathrm{I} / \mathrm{B} / \mathrm{E} / \mathrm{S}$ regime shift. Since the unexpected portion of $E P S_{D i f f}$ is correlated with unexpected returns (UR), measurement error creates an upward bias in $R e v \hat{E} R C_{\text {Street }}$, and consequently, a downward bias in the reciprocal of reverse Street ERC in period 1 (and not period 2). In short, the estimates are biased upward for GAAP ERC in both periods and for Street ERC in period 2, but the overall direction of bias for Street ERC in period 1 is unclear.

To illustrate how the potential bias on the estimated reverse ERCs may affect the trend in the difference between the reciprocal reverse ERCs, we assume that the true unbiased ERCs and covariances remain constant across the two periods, that is, absent any bias, the difference between the true GAAP and Street ERCs is constant. We plot the true ERCs and the estimated ERCs in Figure A1.

Figure A1. Bias-induced patterns in reciprocals of reverse ERCs

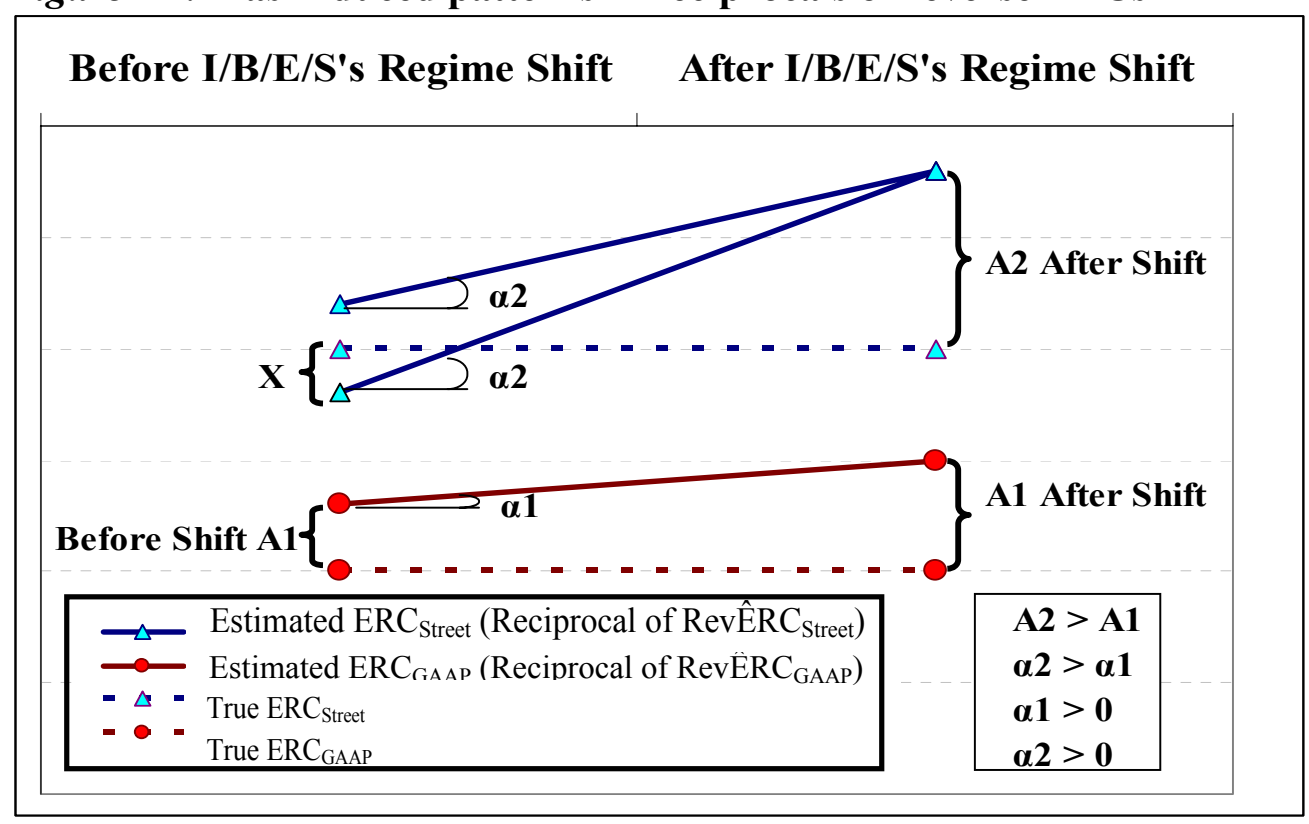


The dotted and solid lines in Figure A1 connect true ERCs and inferred ERC estimates (i.e., reciprocals of reverse ERCs), respectively, before and after the $\mathrm{I} / \mathrm{B} / \mathrm{E} / \mathrm{S}$ regime shift. The reciprocals of reverse ERCs always deviate from the true ERC values, with bias magnitudes A1, A2, and X corresponding to the expressions from Table A1.

Next, we argue that two propositions regarding possible bias-induced patterns hold: (1) the magnitude of the bias for the reciprocal of the reverse Street ERC is larger than its counterpart for GAAP ERC in the period after I/B/E/S's regime shift, and (2) the slope of the trend for the reciprocal of reverse Street ERC is always larger than the corresponding slope for GAAP ERC estimate. Taken together, these two propositions imply that potential biases in the reverse regressions design would work against finding an insignificant difference in ERCs and ERC trends. In terms of the bias expressions summarized in Table 1A, each proposition is equivalent to a corresponding inequality:

(1) "Inequality 1": A1(after shift) < A2(after shift);

(2) "Inequality 2": A1(after shift)-A1(before shift) < A2(after shift)-X(before shift).

Inequality 1 holds at all times, since the following two conditions are satisfied always: first, $\operatorname{cov}\left(F E_{\text {Street }}, U R\right)<\operatorname{cov}\left(F E_{\text {GAAP }}, U R\right)=\operatorname{cov}\left(F E_{\text {Street }}, U R\right)+\operatorname{cov}\left(F E_{\text {Diff }}, U R\right)$, and second, $\operatorname{var}\left(\varepsilon_{1}\right)<\operatorname{var}\left(\varepsilon_{2}\right)=\operatorname{var}\left(\varepsilon_{1}+F E_{D i f f}\right) .{ }^{27}$ Turning to Inequality 2, we first show that it holds when the variance of the error term, $\varepsilon$, is constant over time. In that case, A1(after shift) $=\mathrm{A} 1($ before shift $)$ and $\mathrm{A} 2($ after shift $)=\mathrm{A} 2$ (before shift $)>\mathrm{X}($ before shift $),{ }^{28}$ and thus Inequality 2 is equivalent to comparing zero to a positive value. Next, we show that Inequality 2 also holds

\footnotetext{
${ }^{27}$ We make the restrictive assumption that $F E_{\text {Diff }}$ is uncorrelated with $F E_{\text {Street }}$.

${ }^{28}$ The latter inequality holds following the chain of arguments below:

$$
\begin{aligned}
X & =\frac{E R C_{\text {Street }}+A 2}{1+B\left(E R C_{\text {Street }}+A 2\right)}-E R C_{\text {Street }} \Rightarrow\left[X+E R C_{\text {Street }}\right]=\frac{E R C_{\text {Street }}+A 2}{1+B\left(E R C_{\text {Street }}+A 2\right)}<E R C_{\text {Street }}+A 2 \\
& \Rightarrow X<A 2
\end{aligned} .
$$
}


if the variance of the error term, $\varepsilon$, increases over time. In that case, first note that A2(after shift) - A2(before shift) $<$ A2(after shift) $-X$ (before shift), since $X$ (before shift) $<$ A2(before shift). All that is left to show is that $\mathrm{A} 1$ (after shift) - A1(before shift) $<\mathrm{A} 2$ (after shift) - A2(before shift). Recall that we assume that true ERCs and true covariances and variances are constant over time. Therefore, the latter inequality can be expanded into (the subscripts "before" and "after" refer, respectively, to error terms before and after the $\mathrm{I} / \mathrm{B} / \mathrm{E} / \mathrm{S}$ regime shift):

$$
\begin{aligned}
& \frac{\left\lfloor\operatorname{var}\left(\varepsilon_{\text {lafter }}\right)-\operatorname{var}\left(\varepsilon_{\text {lbefore }}\right)\right\rfloor}{\operatorname{cov}\left(F E_{G A A P}, U R\right)}<\frac{\left\lfloor\operatorname{var}\left(\varepsilon_{\text {affer }}\right)-\operatorname{var}\left(\varepsilon_{2 \text { before }}\right)\right\rfloor}{\operatorname{cov}\left(F E_{\text {Street }}, U R\right)} \\
& \Leftrightarrow \quad \frac{\left\lfloor\operatorname{var}\left(\varepsilon_{\text {laffer }}\right)-\operatorname{var}\left(\varepsilon_{\text {1before }}\right)\right\rfloor}{\operatorname{cov}\left(F E_{G A A P}, U R\right)}<\frac{\left\lfloor\operatorname{var}\left(\varepsilon_{\text {laffer }}+F E_{\text {Dif }}\right)-\operatorname{var}\left(\varepsilon_{\text {lbefore }}+F E_{\text {Diff }}\right)\right\rfloor}{\operatorname{cov}\left(F E_{\text {Street }}, U R\right)} \\
& <=>\frac{1}{\operatorname{cov}\left(F E_{G A A P}, U R\right)}<\frac{1}{\operatorname{cov}\left(F E_{\text {Street }}, U R\right)} \\
& <=\quad \operatorname{cov}\left(F E_{\text {Street }}, U R\right)<\operatorname{cov}\left(F E_{G A A P}, U R\right) .
\end{aligned}
$$

As noted previously, the last inequality holds at all times since $\operatorname{cov}\left(F E_{\text {Street }}, U R\right)<\operatorname{cov}\left(F E_{G A A P}, U R\right)=\operatorname{cov}\left(F E_{\text {Street }}, U R\right)+\operatorname{cov}\left(F E_{\text {Diff }}, U R\right)$.

In short, the first proposition holds at all times, and the second proposition holds when the variance of the error term, $\varepsilon$, is constant or increasing. Conceptually, the variance of the error $\varepsilon$ is proportional to the amount of information received by the market from sources unrelated to accounting earnings. Therefore, the assumption of increasing error variance is consistent with the evidence from prior research on the market increasingly using information not summarized by bottom-line numbers, as well as the overall increase in idiosyncratic return volatility (e.g. Francis et al., 2002; Campbell et al., 2001; Rajgopal and Venkatachalam, 2005).

Overall, the direction of the biases is in favor of finding a significant divergence pattern in the reciprocals of reverse ERCs. Put differently, the potential biases in the estimated reverse ERCs 
are against finding the documented empirical results, that is, an insignificant increase in the difference between the estimated reverse ERCs, and hence, the reciprocal of the reverse ERCs. 


\section{References}

Abarbanell , J. and R. Lehavy. (2006). "Letting the "Tail Wag the Dog": The Debate over GAAP versus Street Earnings Revisited." Forthcoming, Contemporary Accounting Research.

Abarbanell , J. and R. Lehavy. (2002). "Differences in Commercial Database Reported Earnings: Implication for Empirical Research." Working Paper. University of North Carolina and University of Michigan.

Beaver W. H., R. Lambert, and S. Ryan. (1987). "The Information Content of Security Prices: A Second Look." Journal of Accounting and Economics 9, 139-157.

Berger, P. (2005). "Discussion of 'Are Investor Misled by 'Pro Forma' Earnings?"” Contemporary Accounting Research 22, 965-976.

Bhattacharya, N., E. Black, T. Christensen, and C. Larson. (2003). "Assessing the Relative Informativeness and Performance of Pro Forma Earnings and GAAP Operating Earnings." Journal of Accounting and Economic 36, 285-319.

Bradshaw, M. (2003). "A Discussion of 'Assessing the Relative Informativeness and Permanence of Pro Forma Earnings and GAAP Operating Earnings"'. Journal of Accounting and Economics 36, 321 - 335.

Bradshaw, M. and R. Sloan. (2002). "GAAP versus The Street: An Empirical Assessment of Two Alternative Definitions of Earnings.” Journal of Accounting Research 40, 41-66.

Brown, L. (2001). "A Temporal Analysis of Earnings Surprises: Profits versus Losses.” Journal of Accounting Research 39, 221-241.

Brown, L. and K. Sivakumar. (2003). "Comparing the Value Relevance of Two Operating Income Measures." Review of Accounting Studies 8, 561-572.

Campbell, J. Y., M. Lettau, B. G. Malkiel, and Y. Xu. (2001). "Have Individual Stocks Become More Volatile? An Empirical Exploration of Idiosyncratic Risk." Journal of Finance 56, 1-43.

Collins, D. and S.P. Kothari. (1989). "An Analysis of Intemporal and Cross Sectional Determinants of Earnings Response Coefficients." Journal of Accounting and Economics 11, 143-181.

Collins, D., O. Li, and H. Xie. (2005). "What Drives the Increased Informativeness of Earnings Announcements Over Time?" Working Paper, University of Iowa.

Doyle, J., R. Lundholm, and M. Soliman. (2003). "The Predictive Value of Expenses Excluded from 'Pro Forma' Earnings.” Review of Accounting Studies 8, 145-174. 
Doyle, J., R. Lundholm, and M. Soliman. (2006). "The Extreme Future Stock Returns Following I/B/E/S Earnings Surprises.” Journal of Accounting Research 44, 849-887.

Doyle, J. and M. Soliman. (2004). "Do Managers Define 'Street' Earnings to Meet or Beat Analyst Forecasts?” Working Paper. University of Utah and Stanford University.

Francis, J., K. Schipper, and L. Vincent. (2002). "Expanded Disclosures and the Increased Usefulness of Earnings Announcements.” The Accounting Review 77, 515-546.

I/B/E/S. (2001). "The I/B/E/S Glossary, A Guide to Understanding I/B/E/S Terms and Conventions." I/B/E/S International Inc.

Johnson, B. and W. Schwartz. (2005). "Are Investors Mislead by "Pro-Forma" Earning?" Contemporary Accounting Research 22, 915-963.

Landsman, W. and E. Maydew. (2002). "Has the Information Content of Quarterly Earnings Announcements Declined in the Past Three Decades?" Journal of Accounting Research 40, 797808.

Lougee, B. and C. Marquardt. (2004). "Earnings Informativeness and Strategic Disclosure: An Empirical Examination of 'Pro Forma' Earnings.” The Accounting Review 79, 769-795.

O’Brien, P. (1988). “Analysts' Forecasts as Earnings Expectations.” Journal of Accounting and Economics 10, 53-83.

Rajgopal, S. and M. Venkatachalam. (2005). "Financial Reporting Quality and Idiosyncratic Return Volatility over the Last Four Decades." Working paper, University of Washington and Duke University. 
Figure 1. True (Unbiased) ERC vs. Estimated ERC with Measurement Errors: The $I / B / E / S$ Adjustment Error and GAAP Expectation Error

Panel A. Downward bias from $I / B / E / S$ Adjustment Error

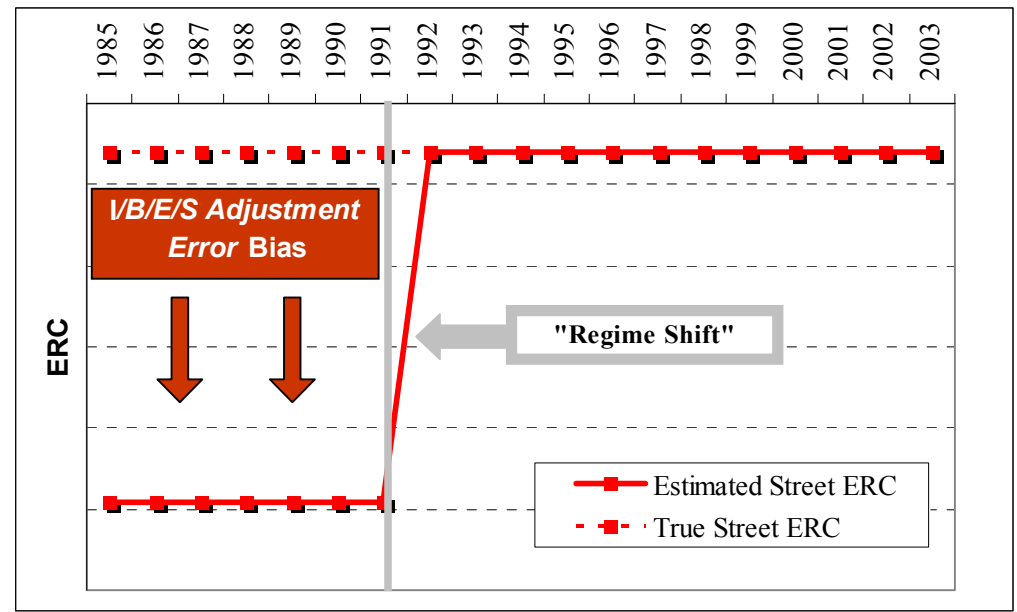

Panel B. Downward bias from GAAP Expectation Error

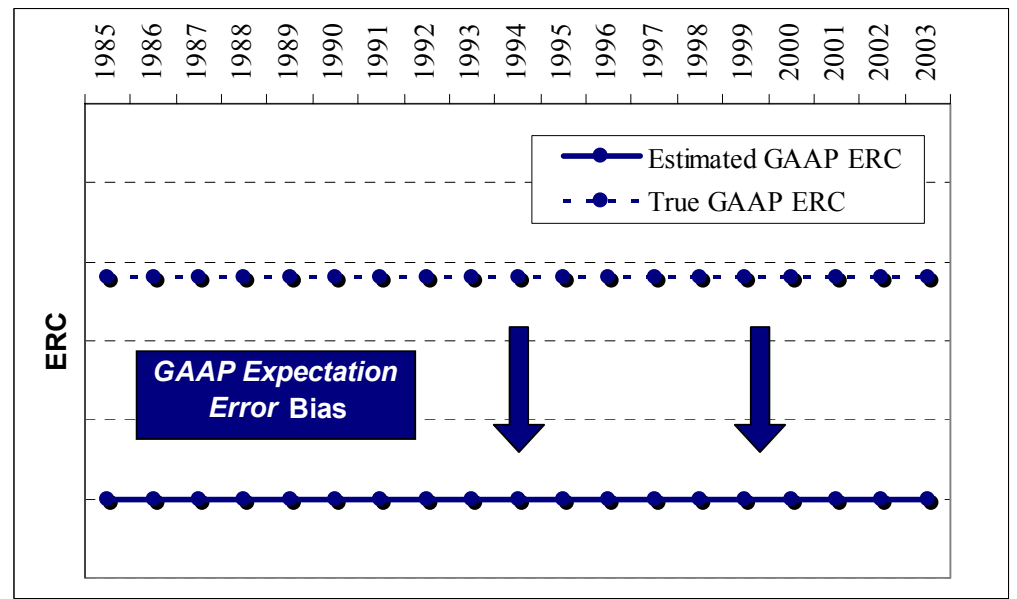

Panel C. Downward Biases from

I/B/E/S Adjustment Error and GAAP Expectation Error

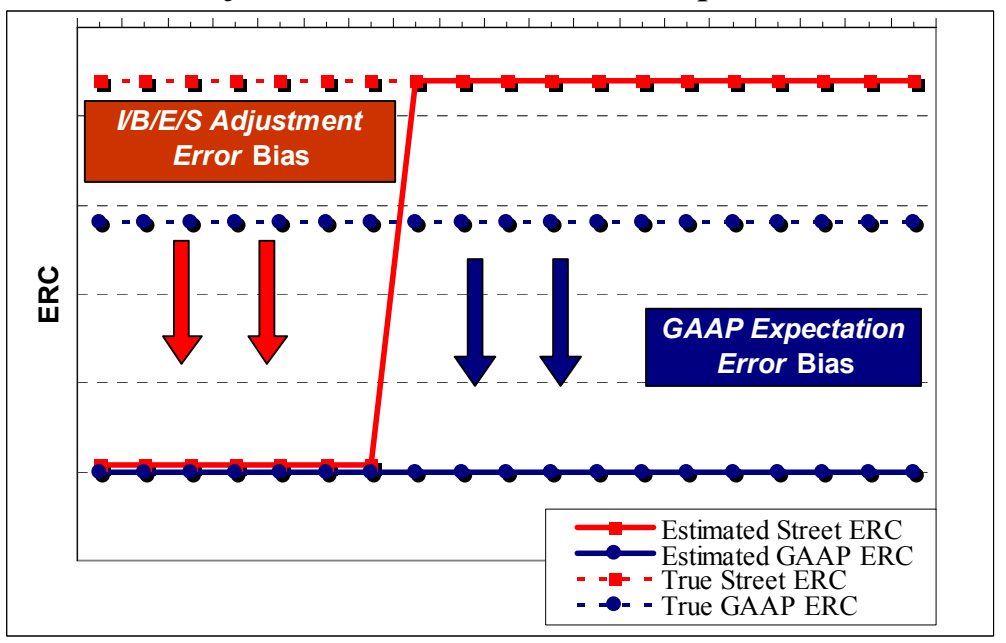

The figure illustrates the effects that the two types of measurement errors in earnings surprises: the $I / B / E / S$ Adjustment Error and the GAAP Expectation Error, have on the observed patterns in estimated GAAP and Street earnings response coefficients. 
Figure 2. Time-series plots of GAAP and Street ERCs, 1985-2003

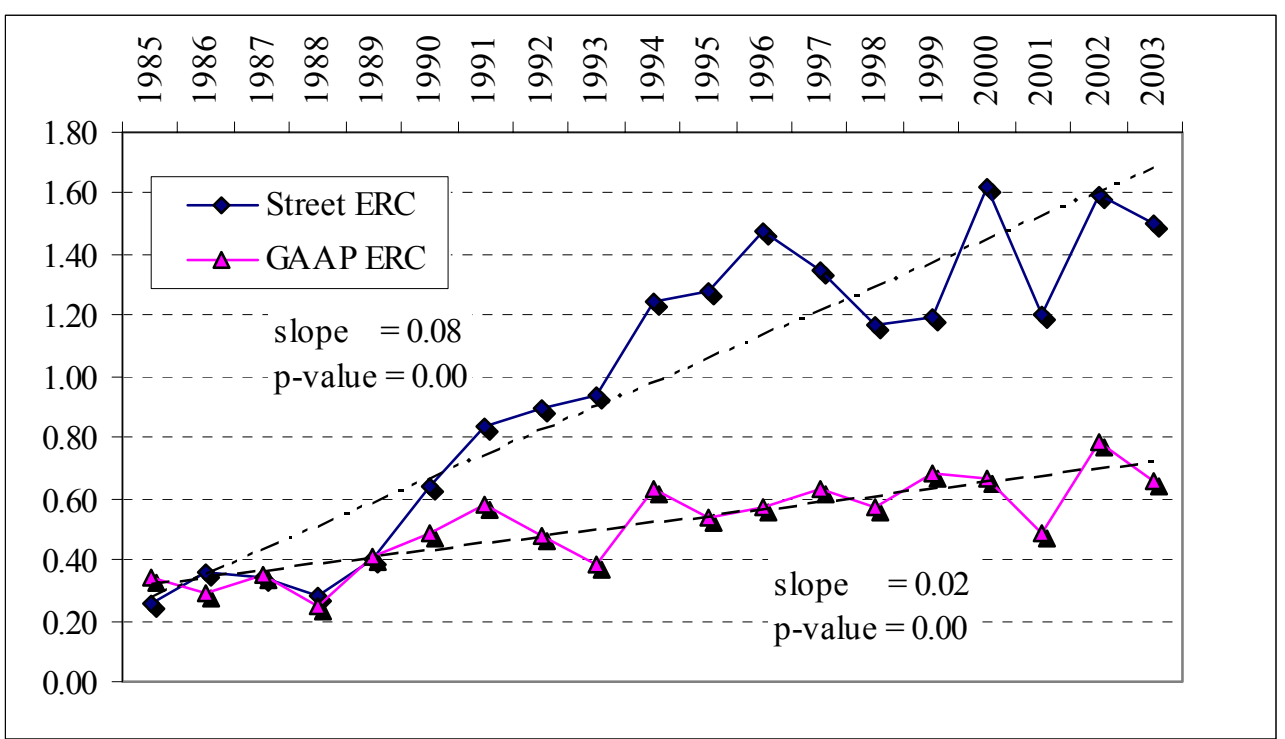

Figure 2 plots year-by-year Street and GAAP ERCs. Street ERC is a slope coefficient from a regression of a 3-day buy-and-hold market-adjusted return around earnings announcement date on forecast error computed as $\mathrm{I} / \mathrm{B} / \mathrm{E} / \mathrm{S}$ earnings per share minus the most recent $\mathrm{I} / \mathrm{B} / \mathrm{E} / \mathrm{S}$ forecast issued before earnings announcement date (within a 90 days period) scaled by beginning of the quarter share price. GAAP ERC is a slope coefficient from a regression of a 3-day buy-and-hold market-adjusted return around earnings announcement date on forecast error computed as GAAP earnings per share minus the most recent $\mathrm{I} / \mathrm{B} / \mathrm{E} / \mathrm{S}$ forecast issued before earnings announcement date (within a 90 days period) scaled by beginning of the quarter share price. 
Figure 3. Time-series plots of GAAP and Street ERCs: Inverse of Variance and Covariance, 1985-2003

Panel A. Inverse of variance for GAAP and Street forecast errors

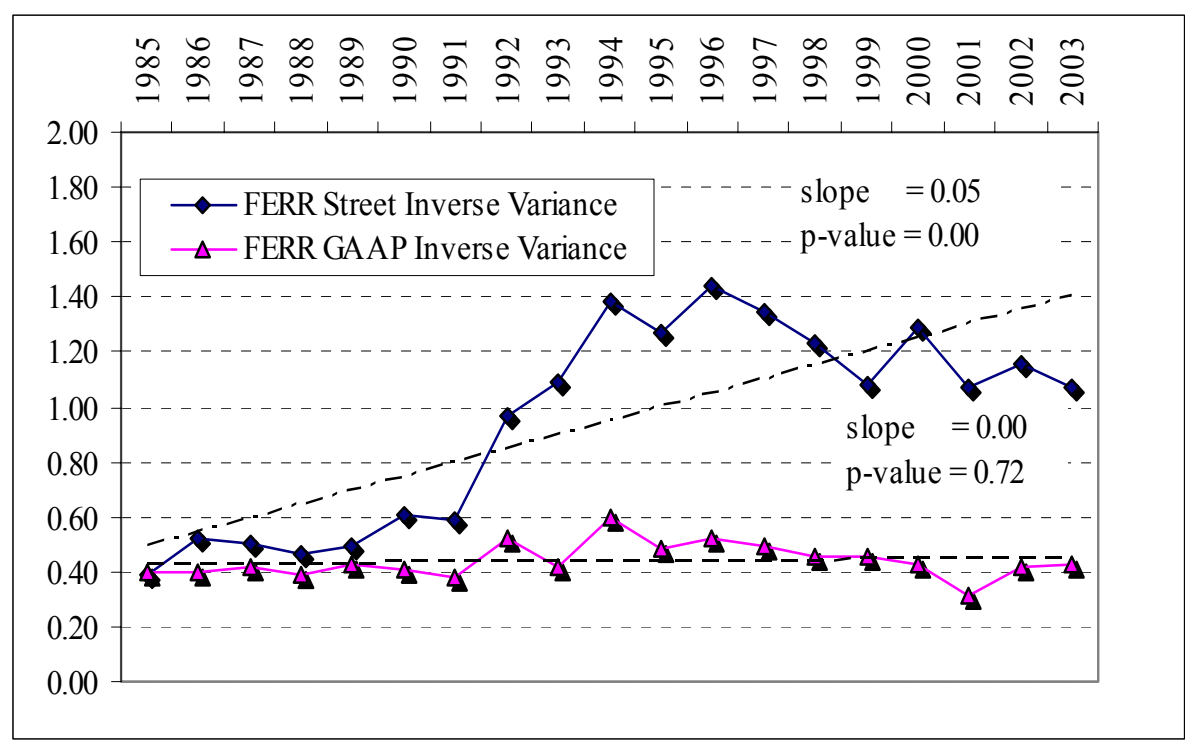

Panel B. Covariance of 3-day returns with GAAP or Street forecast errors

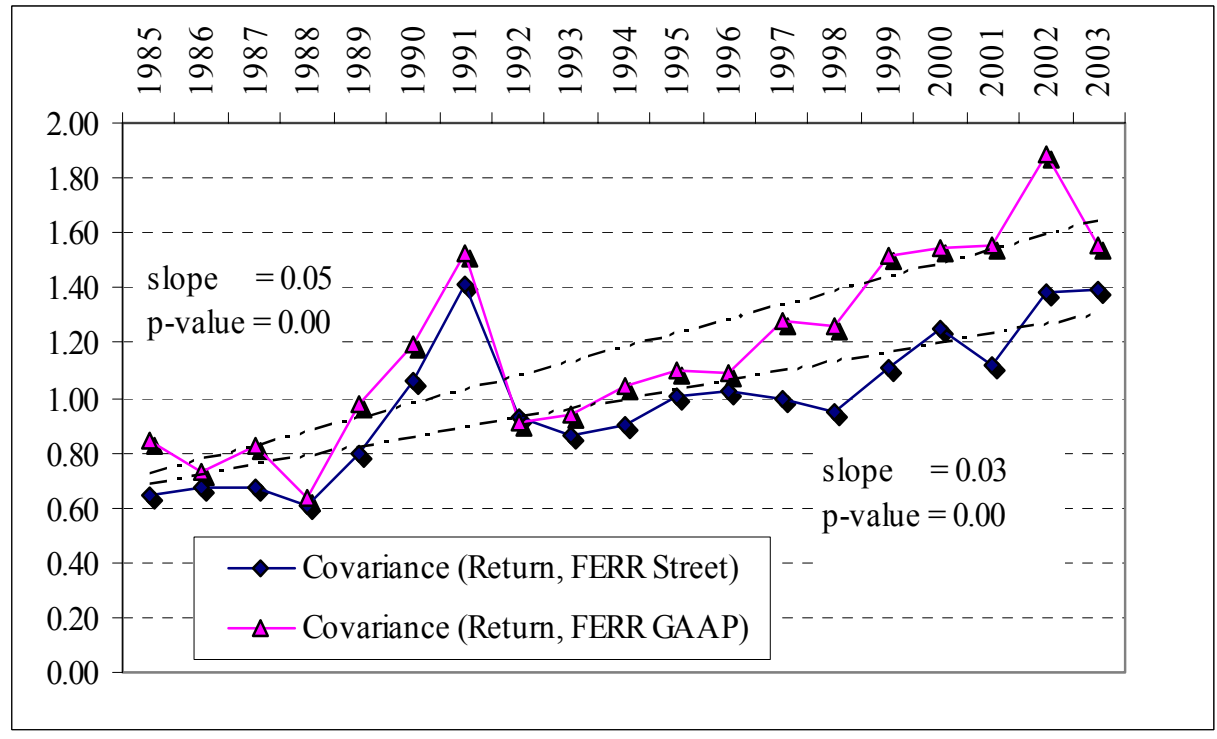

Panel B contains inverse of variance for Street and GAAP forecast errors. Panel C contains covariance values between 3-day buy-and-hold market-adjusted returns around earnings announcement date and Street or GAAP forecast errors. Forecast errors and returns are multiplied by 100. Plots contain trend lines and corresponding slopes and slope pvalues for regressions of ERCs, inverse of variance or covariance values on the year variable (1985 to 2003). 
Figure 4. Time-Series Plots of Reverse ERCs for GAAP and Street Forecast Errors, 1985-2003

Panel A. Reverse ERCs

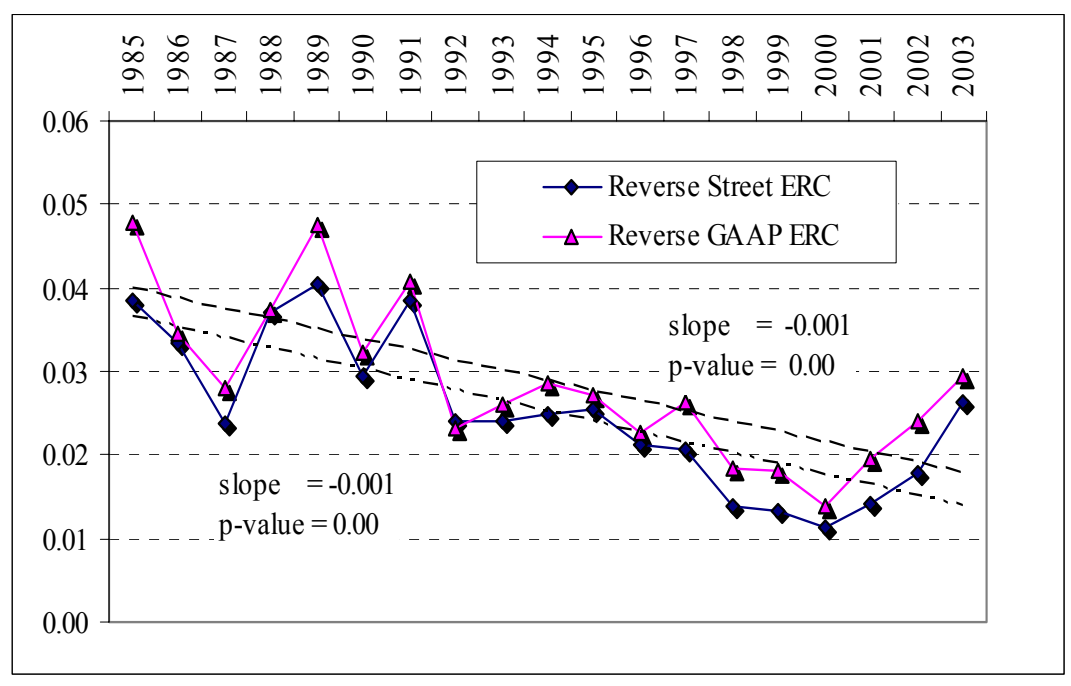

Panel B. Reciprocals of reverse ERCs

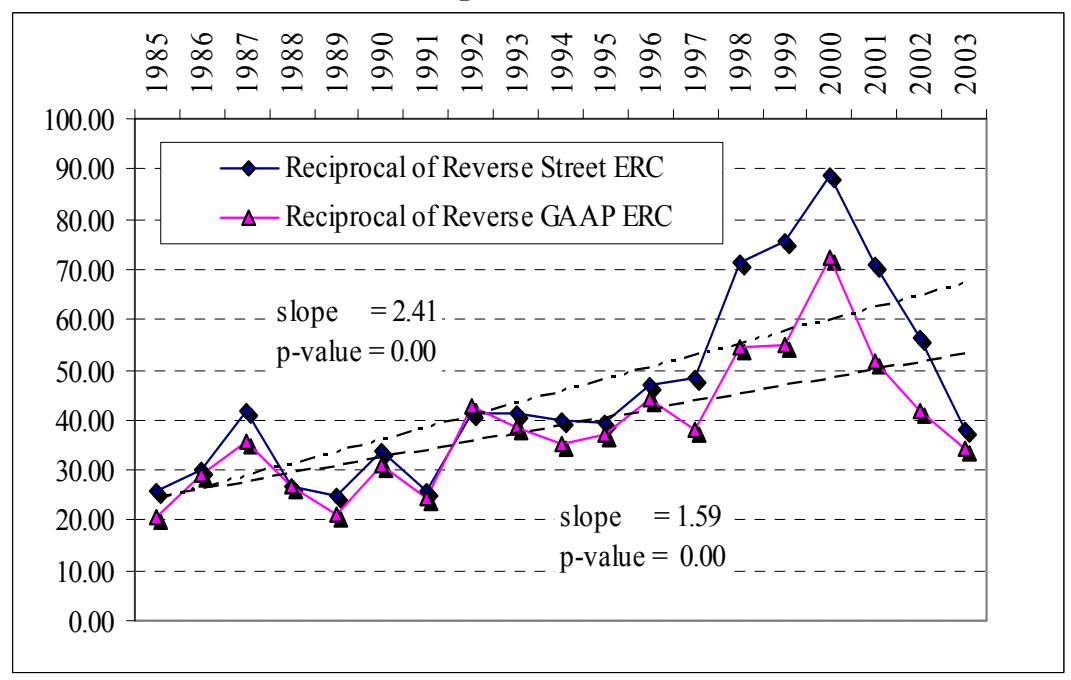

Panel C. Scaled reverse and original ERCs

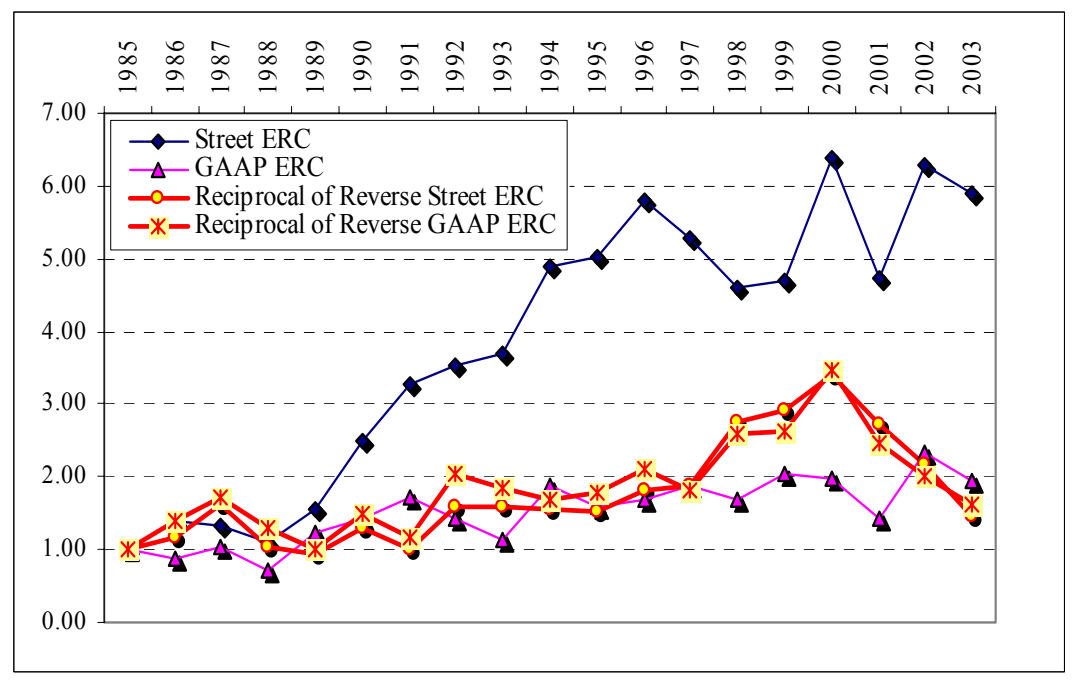


Panel A contains Street and GAAP reverse ERCs. Street reverse ERC is a slope coefficient from a regression of Street forecast error on 3-day buy-and-hold market-adjusted returns around earnings announcement dates, where forecast error is computed as $\mathrm{I} / \mathrm{B} / \mathrm{E} / \mathrm{S}$ earnings per share minus the most recent $\mathrm{I} / \mathrm{B} / \mathrm{E} / \mathrm{S}$ forecast issued before the earnings announcement date (within a 90 days period) scaled by beginning of the quarter share price. GAAP reverse ERC is a slope coefficient from a regression of GAAP forecast error on a 3-day buy-and-hold market-adjusted returns around earnings announcement dates, where forecast error is computed as GAAP earnings per share minus the most recent $\mathrm{I} / \mathrm{B} / \mathrm{E} / \mathrm{S}$ forecast issued before the earnings announcement date (within a 90 days period) scaled by beginning of the quarter share price. Panel B contains reciprocals of Street and GAAP reverse ERCs (1/[Reverse ERC]). Panel C plots the original ERC estimates from Figure 3 and the reciprocals of the reverse ERCs. To construct each curve, all observations are scaled by the 1985 value of the corresponding ERC or reciprocal for reverse ERC. Plots contain trend lines and corresponding slopes and slope p-values for regressions of ERCs, and reciprocals of inverse ERCs on the year variable (1985 to 2003). 


\section{Table 1. Trends in Earnings Response Coefficients for Street and GAAP Forecast Errors}

The table presents results for OLS regressions of announcement period returns on Street or GAAP forecast errors. Street and GAAP columns present coefficients from regressions using Street and GAAP forecast errors respectively. Difference columns contain differences between coefficients from Street and GAAP regressions. Panel A reports results of Model I regression: RET $=$ Intercept + YEAR + FE + FE*YEAR. Panel B reports results of Model II regression: RET $=$ Intercept + POST91 + FE + FE*POST91. RET is a 3-day buy-and-hold market-adjusted return around earnings announcement dates from I/B/E/S; YEAR - coded as $0-18$ for each year in $(1985,2003)$ time period; FE - GAAP or Street forecast error computed as corresponding earnings per share minus the most recent $\mathrm{I} / \mathrm{B} / \mathrm{E} / \mathrm{S}$ forecast issued before the earnings announcement date (within a 90 days period) scaled by beginning of the quarter share price; POST91 - coded as 1 for each year in $(1992,2003)$ time period and 0 otherwise. Forecast errors and returns are multiplied by 100 . P-values for the coefficients are reported in parentheses.

Panel A. Model I: Continuous Time Trend

\begin{tabular}{|c|c|c|c|c|c|c|}
\hline \multirow[b]{2}{*}{$\begin{array}{l}\text { Independent } \\
\text { Variables }\end{array}$} & \multicolumn{3}{|c|}{$1985-2003$} & \multicolumn{3}{|c|}{$1985-1997$} \\
\hline & Street & GAAP & Difference & Street & GAAP & Difference \\
\hline Intercept & $\begin{array}{l}0.084 \\
(0.04)\end{array}$ & $\begin{array}{l}-0.049 \\
(0.23)\end{array}$ & $\begin{array}{l}0.132 \\
(0.02)\end{array}$ & $\begin{array}{l}0.043 \\
(0.31)\end{array}$ & $\begin{array}{l}-0.026 \\
(0.54)\end{array}$ & $\begin{array}{l}0.069 \\
(0.25)\end{array}$ \\
\hline YEAR & $\begin{array}{l}0.016 \\
(0.00)\end{array}$ & $\begin{array}{l}0.034 \\
(0.00)\end{array}$ & $\begin{array}{l}-0.018 \\
(0.00)\end{array}$ & $\begin{array}{l}0.019 \\
(0.00)\end{array}$ & $\begin{array}{l}0.028 \\
(0.00)\end{array}$ & $\begin{array}{l}-0.009 \\
(0.23)\end{array}$ \\
\hline FE & $\begin{array}{l}0.267 \\
(0.00)\end{array}$ & $\begin{array}{l}0.336 \\
(0.00)\end{array}$ & $\begin{array}{l}-0.068 \\
(0.09)\end{array}$ & $\begin{array}{l}0.113 \\
(0.00)\end{array}$ & $\begin{array}{l}0.294 \\
(0.00)\end{array}$ & $\begin{array}{l}-0.181 \\
(0.00)\end{array}$ \\
\hline FE*YEAR & $\begin{array}{l}0.077 \\
(0.00)\end{array}$ & $\begin{array}{l}0.020 \\
(0.00)\end{array}$ & $\begin{array}{l}0.057 \\
(0.00)\end{array}$ & $\begin{array}{l}0.111 \\
(0.00)\end{array}$ & $\begin{array}{l}0.027 \\
(0.00)\end{array}$ & $\begin{array}{l}0.084 \\
(0.00)\end{array}$ \\
\hline Adj. $R^{2}$ & $2.26 \%$ & $1.35 \%$ & & $2.57 \%$ & $1.48 \%$ & \\
\hline No. of Obs. & 188,732 & 188,732 & & 112,962 & 112,962 & \\
\hline
\end{tabular}

Panel B. Model II: POST-1992 Dummy

\begin{tabular}{|c|c|c|c|c|c|c|}
\hline \multirow[b]{2}{*}{$\begin{array}{l}\text { Independent } \\
\text { Variables }\end{array}$} & \multicolumn{3}{|c|}{$1985-2003$} & \multicolumn{3}{|c|}{ 1985-1997 } \\
\hline & Street & GAAP & Difference & Street & GAAP & Difference \\
\hline Intercept & $\begin{array}{l}0.127 \\
(0.00)\end{array}$ & $\begin{array}{l}0.093 \\
(0.01)\end{array}$ & $\begin{array}{l}0.035 \\
(0.50)\end{array}$ & $\begin{array}{l}0.127 \\
(0.00)\end{array}$ & $\begin{array}{l}0.093 \\
(0.00)\end{array}$ & $\begin{array}{l}0.035 \\
(0.41)\end{array}$ \\
\hline POST91 & $\begin{array}{l}0.166 \\
(0.00)\end{array}$ & $\begin{array}{l}0.282 \\
(0.00)\end{array}$ & $\begin{array}{l}-0.116 \\
(0.04)\end{array}$ & $\begin{array}{l}0.100 \\
(0.01)\end{array}$ & $\begin{array}{l}0.144 \\
(0.00)\end{array}$ & $\begin{array}{l}-0.045 \\
(0.40)\end{array}$ \\
\hline FE & $\begin{array}{l}0.462 \\
(0.00)\end{array}$ & $\begin{array}{l}0.408 \\
(0.00)\end{array}$ & $\begin{array}{l}0.054 \\
(0.12)\end{array}$ & $\begin{array}{l}0.462 \\
(0.00)\end{array}$ & $\begin{array}{l}0.408 \\
(0.00)\end{array}$ & $\begin{array}{l}0.054 \\
(0.06)\end{array}$ \\
\hline FE*POST91 & $\begin{array}{l}0.832 \\
(0.00)\end{array}$ & $\begin{array}{l}0.185 \\
(0.00)\end{array}$ & $\begin{array}{l}0.647 \\
(0.00)\end{array}$ & $\begin{array}{l}0.744 \\
(0.00)\end{array}$ & $\begin{array}{l}0.138 \\
(0.00)\end{array}$ & $\begin{array}{l}0.606 \\
(0.00)\end{array}$ \\
\hline Adj. $\mathrm{R}^{2}$ & $2.23 \%$ & $1.32 \%$ & & $2.47 \%$ & $1.45 \%$ & \\
\hline No. of Obs. & 188,732 & 188,732 & & 112,962 & 112,962 & \\
\hline
\end{tabular}




\section{Table 2. Trends in Reverse ERCs for Street and GAAP Forecast Errors}

The table presents results for OLS regressions of Street or GAAP forecast errors on announcement period returns. Street and GAAP columns present coefficients from regressions using Street and GAAP forecast errors respectively. Difference columns contain differences between coefficients from Street and GAAP regressions. Panel A reports results of Model I regression: FE $=$ Intercept + YEAR + RET + RET*YEAR. Panel B reports results of Model II regression: $\mathrm{FE}=$ Intercept + POST91 $+\mathrm{RE3}+\mathrm{RET} *$ POST91. RET is a 3-day buy-and-hold market-adjusted return around earnings announcement dates from I/B/E/S; YEAR - coded as $0-18$ for each year in $(1985,2003)$ time period; FE - GAAP or Street forecast error computed as corresponding earnings per share minus the most recent I/B/E/S forecast issued before the earnings announcement date (within a 90 days period) scaled by beginning of the quarter share price; POST91 - coded as 1 for each year in $(1992$ - 2003) time period and 0 otherwise. Forecast errors and returns are multiplied by 100 . P-values for the coefficients are reported in parentheses.

Panel A. Model I: Continuous Time Trend

\begin{tabular}{|c|c|c|c|c|c|c|}
\hline \multirow[b]{2}{*}{$\begin{array}{l}\text { Independent } \\
\text { Variables }\end{array}$} & \multicolumn{3}{|c|}{$1985-2003$} & \multicolumn{3}{|c|}{$1985-1997$} \\
\hline & Street & GAAP & Difference & Street & GAAP & Difference \\
\hline Intercept & $\begin{array}{l}-0.238 \\
(0.00)\end{array}$ & $\begin{array}{l}-0.098 \\
(0.00)\end{array}$ & $\begin{array}{l}-0.140 \\
(0.00)\end{array}$ & $\begin{array}{l}-0.258 \\
(0.00)\end{array}$ & $\begin{array}{l}-0.132 \\
(0.00)\end{array}$ & $\begin{array}{l}-0.126 \\
(0.00)\end{array}$ \\
\hline YEAR & $\begin{array}{l}0.019 \\
(0.00)\end{array}$ & $\begin{array}{l}-0.003 \\
(0.00)\end{array}$ & $\begin{array}{l}0.021 \\
(0.00)\end{array}$ & $\begin{array}{l}0.022 \\
(0.00)\end{array}$ & $\begin{array}{l}0.004 \\
(0.00)\end{array}$ & $\begin{array}{l}0.019 \\
(0.00)\end{array}$ \\
\hline RET & $\begin{array}{l}0.035 \\
(0.00)\end{array}$ & $\begin{array}{l}0.037 \\
(0.00)\end{array}$ & $\begin{array}{l}-0.002 \\
(0.35)\end{array}$ & $\begin{array}{l}0.038 \\
(0.00)\end{array}$ & $\begin{array}{l}0.040 \\
(0.00)\end{array}$ & $\begin{array}{l}-0.003 \\
(0.32)\end{array}$ \\
\hline RET*YEAR & $\begin{array}{l}-0.001 \\
(0.00)\end{array}$ & $\begin{array}{l}-0.001 \\
(0.00)\end{array}$ & $\begin{array}{l}0.000 \\
(0.25)\end{array}$ & $\begin{array}{l}-0.001 \\
(0.00)\end{array}$ & $\begin{array}{l}-0.001 \\
(0.00)\end{array}$ & $\begin{array}{l}0.000 \\
(0.91)\end{array}$ \\
\hline Adj. $R^{2}$ & $2.77 \%$ & $1.32 \%$ & & $2.56 \%$ & $1.45 \%$ & \\
\hline No. of Obs. & 188,732 & 188,732 & & 112,962 & 112,962 & \\
\hline
\end{tabular}

Panel B. Model II: POST-1992 Dummy

\begin{tabular}{|c|c|c|c|c|c|c|}
\hline \multirow[b]{2}{*}{$\begin{array}{l}\text { Independent } \\
\text { Variables }\end{array}$} & \multicolumn{3}{|c|}{$1985-2003$} & \multicolumn{3}{|c|}{$\begin{array}{l}1985-1997 \\
\end{array}$} \\
\hline & Street & GAAP & Difference & Street & GAAP & Difference \\
\hline Intercept & $\begin{array}{l}-0.192 \\
(0.00)\end{array}$ & $\begin{array}{l}-0.132 \\
(0.00)\end{array}$ & $\begin{array}{l}-0.060 \\
(0.00)\end{array}$ & $\begin{array}{l}-0.192 \\
(0.00)\end{array}$ & $\begin{array}{l}-0.132 \\
(0.00)\end{array}$ & $\begin{array}{l}-0.060 \\
(0.00)\end{array}$ \\
\hline POST91 & $\begin{array}{l}0.195 \\
(0.00)\end{array}$ & $\begin{array}{l}0.008 \\
(0.36)\end{array}$ & $\begin{array}{l}0.188 \\
(0.00)\end{array}$ & $\begin{array}{l}0.157 \\
(0.00)\end{array}$ & $\begin{array}{l}0.041 \\
(0.00)\end{array}$ & $\begin{array}{l}0.115 \\
(0.00)\end{array}$ \\
\hline RET & $\begin{array}{l}0.034 \\
(0.00)\end{array}$ & $\begin{array}{l}0.037 \\
(0.00)\end{array}$ & $\begin{array}{l}-0.003 \\
(0.07)\end{array}$ & $\begin{array}{l}0.034 \\
(0.00)\end{array}$ & $\begin{array}{l}0.037 \\
(0.00)\end{array}$ & $\begin{array}{l}-0.003 \\
(0.07)\end{array}$ \\
\hline RET*POST91 & $\begin{array}{l}-0.017 \\
(0.00)\end{array}$ & $\begin{array}{l}-0.016 \\
(0.00)\end{array}$ & $\begin{array}{l}0.000 \\
(0.81)\end{array}$ & $\begin{array}{l}-0.011 \\
(0.00)\end{array}$ & $\begin{array}{l}-0.012 \\
(0.00)\end{array}$ & $\begin{array}{l}0.001 \\
(0.75)\end{array}$ \\
\hline Adj. $\mathrm{R}^{2}$ & $2.63 \%$ & $1.33 \%$ & & $2.55 \%$ & $1.47 \%$ & \\
\hline No. of Obs. & 188,732 & 188,732 & & 112,962 & 112,962 & \\
\hline
\end{tabular}




\section{Table 3. Original and Reverse ERCs for Street and GAAP Forecast Errors}

Street ERC is a slope coefficient from a regression of a 3-day buy-and-hold market-adjusted returns around earnings announcement date on forecast error computed as $\mathrm{I} / \mathrm{B} / \mathrm{E} / \mathrm{S}$ earnings per share minus the most recent $\mathrm{I} / \mathrm{B} / \mathrm{E} / \mathrm{S}$ forecast issued before earnings announcement date (within a 90 days period) scaled by beginning of the quarter share price. GAAP ERC is a slope coefficient from a regression of a 3-day buy-and-hold market-adjusted returns around earnings announcement date on forecast error computed as GAAP earnings per share minus the most recent I/B/E/S forecast issued before earnings announcement date (within a 90 days period) scaled by beginning of the quarter share price. Street reverse ERC is a slope coefficient from a regression of Street forecast error on 3-days returns. GAAP reverse ERC is a slope coefficient from a regression of GAAP forecast error on a 3-day returns. P-values for differences between ERCs and reverse ERCs are reported in parentheses.

\begin{tabular}{|c|c|c|c|c|c|c|c|c|c|}
\hline \multirow{2}{*}{ Year } & \multirow{2}{*}{ No. obs. } & \multicolumn{4}{|c|}{ ERC } & \multicolumn{4}{|c|}{ Reverse ERC } \\
\hline & & Street & GAAP & Street & AAP & Street & GAAP & Street & AAP \\
\hline 1993 & 9,274 & 0.942 & 0.387 & 0.554 & $(0.00)$ & 0.024 & 0.026 & -0.002 & $(0.52)$ \\
\hline 1994 & 12,100 & 1.241 & 0.629 & 0.612 & $(0.00)$ & 0.025 & 0.029 & -0.004 & $(0.13)$ \\
\hline 1995 & 12,615 & 1.278 & 0.538 & 0.740 & $(0.00)$ & 0.025 & 0.027 & -0.002 & $(0.48)$ \\
\hline 1996 & 13,717 & 1.475 & 0.571 & 0.905 & $(0.00)$ & 0.021 & 0.023 & -0.001 & $(0.46)$ \\
\hline 1997 & 14,625 & 1.346 & 0.634 & 0.712 & $(0.00)$ & 0.021 & 0.026 & -0.006 & $(0.00)$ \\
\hline 1998 & 14,537 & 1.169 & 0.572 & 0.597 & $(0.00)$ & 0.014 & 0.018 & -0.004 & $(0.01)$ \\
\hline 1999 & 13,811 & 1.195 & 0.685 & 0.510 & $(0.00)$ & 0.013 & 0.018 & -0.005 & $(0.00)$ \\
\hline 2000 & 13,097 & 1.621 & 0.664 & 0.957 & $(0.00)$ & 0.011 & 0.014 & -0.003 & $(0.08)$ \\
\hline 2001 & 11,639 & 1.207 & 0.485 & 0.722 & $(0.00)$ & 0.014 & 0.019 & -0.005 & $(0.01)$ \\
\hline 2002 & 11,190 & 1.598 & 0.786 & 0.813 & $(0.00)$ & 0.018 & 0.024 & -0.006 & $(0.00)$ \\
\hline 2003 & 11,496 & 1.498 & 0.657 & 0.840 & $(0.00)$ & 0.026 & 0.029 & -0.003 & $(0.21)$ \\
\hline All Years & 138,101 & 1.325 & 0.599 & 0.727 & $(0.00)$ & 0.017 & 0.021 & -0.004 & $(0.00)$ \\
\hline
\end{tabular}

